Portland State University

PDXScholar

\title{
A Comparison of the Effects of Different Video Imagery Upon Adult ESL Students' Comprehension of a Video Narrative
}

Scott Alan Thompson

Portland State University

Follow this and additional works at: https://pdxscholar.library.pdx.edu/open_access_etds

Part of the Bilingual, Multilingual, and Multicultural Education Commons Let us know how access to this document benefits you.

Recommended Citation

Thompson, Scott Alan, "A Comparison of the Effects of Different Video Imagery Upon Adult ESL Students' Comprehension of a Video Narrative" (1994). Dissertations and Theses. Paper 4845.

https://doi.org/10.15760/etd.6721

This Thesis is brought to you for free and open access. It has been accepted for inclusion in Dissertations and Theses by an authorized administrator of PDXScholar. Please contact us if we can make this document more accessible: pdxscholar@pdx.edu. 


\section{THESIS APPROVAL}

The abstract and thesis of Scott Alan Thompson for the Master of Arts in Teaching English to Speakers of Other Languages were presented February 9,1994, and accepted by the thesis commmittee and the department.

COMMITTEE APPROVALS:
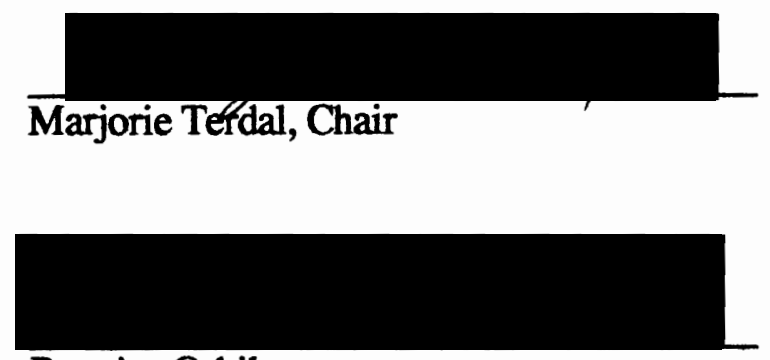

Beatrice Oshika

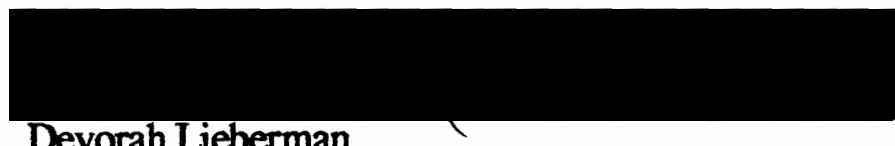

Devorah Lieberman

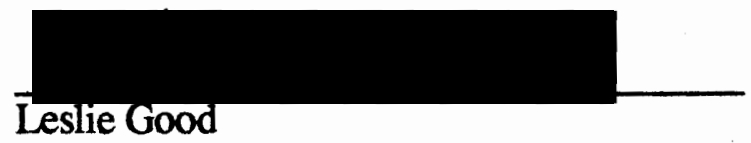

DEPARTMENT APPROVAL:

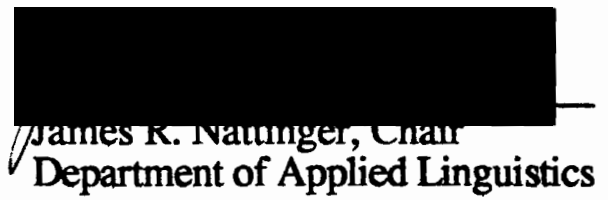

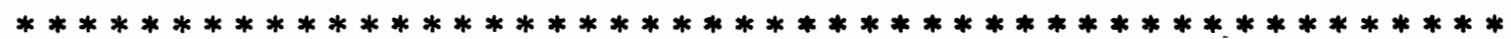

\section{ACCEPTED FOR PORTLAND STATE UNIVERSITY BY THE LIBRARY}

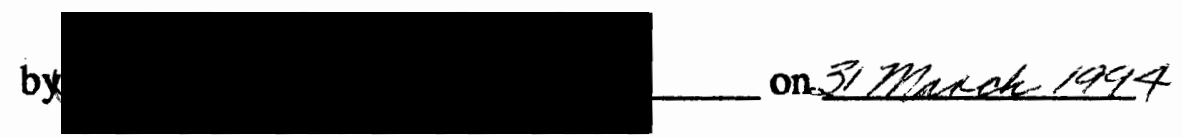




\begin{abstract}
An abstract of the thesis of Scott Alan Thompson for the Masters of Arts in Teaching English to Speakers of Other Languages presented February 9, 1994.
\end{abstract}

Title: A Comparison of the effects of different video imagery upon adult ESL students' comprehension of a video narrative.

This study was meant to provide empirical evidence to support or challenge the assumption that a nonfiction video narrative will be better comprehended by students of ESL if it includes a variety of relevant visual information compared to only seeing a single speaker or "talking head" reciting a narration. The overarching goal of this study was to give teachers of ESL greater knowledge and confidence in using video materials to develop the listening skills of their students. It compared two video tapes which contained the identical soundtrack but different visual information.

The first tape (also called the "lecture tape") showed a single speaker, standing behind a lectern, giving a speech about Costa Rica. The second video (also called the "documentary tape") contained the identical soundtrack of tape one, but included documentary video footage actually filmed in Costa Rica which complemented the narration. A questionnaire of 45 true/false questions was created based on facts given in the narration.

Thirty-nine advanced and fifty-five intermediate university ESL students took part in the study. Approximately half of each group viewed the lecture tape while the other half watched the documentary tape. All students answered the 45 - item questionnaire while viewing their respective video tapes. A thorough item-analysis was then conducted with the initial raw scores of all 94 students, resulting in fifteen questions being omitted from the final analysis. Based on a revised 30 - item questionnaire, the scores of the video and documentary groups were compared within each proficiency level.

The hypothesis of the study was that the documentary tape would significantly improve listening comprehension at the intermediate level but that no significant difference would be found between the advanced lecture and documentary groups. In other words, it 
was predicted that the documentary video would have an interaction effect depending upon proficiency level. However, the results of a 2-way ANOVA did not support the hypothesis. In addition to the ANOVA, a series of t-tests also found no significant difference between the mean scores of the documentary and lecture groups at either the intermediate or the advanced levels

This study was intended to be a beginning to research which may eventually reveal a "taxonomy" of video images from those which enhance listening comprehension the most to those that aid it the least. It contained limitations in the testing procedures which caused the results to be inconclusive. A variety of testing methods was suggested in order to continue research which may reveal such a "video" taxonomy. Given the plethora of video materials that ESL teachers can purchase, record, or create themselves, empirical research is needed to help guide the choices that educators make in choosing video material for their students which will provide meaningful linguistic input. 


\section{A COMPARISON OF THE EFFECTS \\ OF DIFFERENT VIDEO IMAGERY UPON ADULT \\ ESL STUDENTS' COMPREHENSION OF A \\ VIDEO NARRATIVE}

by

SCOTT ALAN THOMPSON

A thesis submitted in partial fulfillment of the requirements for the degree of

\section{MASTER OF ARTS}

in

TEACHING ENGLISH TO SPEAKERS OF OTHER LANGUAGES

Portland State University

1994 


\section{ACKNOWLEDGEMENTS}

I would like to acknowledge the continual patience and support of my parents, John and Betty, my sister, Kathleen, and my best friend Jenna Mayhew. Thanks for listening, waiting, and not giving up hope. I also want to recognize the generosity of Scott and Charlene Wilson, who opened their home and gave me a place to work and live during my studies.

I would also like to thank Deborah Adams, who not only volunteered her time to calculate the statistics for this study, but also demonstrated remarkable flexibility and patience in helping explain the procedures that were done.

Finally, I would like to thank my thesis advisor Marjorie Terdal, who spent hours thoroughly reading each version of the thesis, in the midst her busy teaching schedule, and giving me valuable comments and encouragement. 


\section{TABLE OF CONTENTS}

PAGE

ACKNOWLEDGEMENTS . . . . . . . . . . . . . . . . . ii LIST OF TABLES $\ldots \ldots \ldots \ldots \ldots$

LIST OF FIGURES $\ldots \ldots \ldots \ldots \ldots$. . . . . . . . . . . . . . . .

\section{CHAPTER}

I

INTRODUCTION

Statement of Hypothesis . . . . . . . . . . . . . 6

II REVIEW OF LITERATURE . . . . . . . . . . . 7

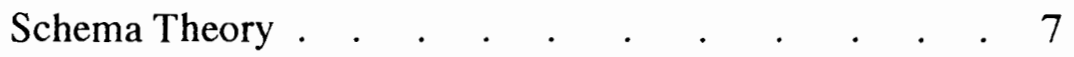

Schema Theory and Reading . . . . . . . . . 10

The Decoding Process . . . . . . . . . . 11

Ausubel's Theory of Meaningful Learning . . . . 12

Listening Comprehension . . . . . . . . . . 13

Psycholinguistic Research and Listening . . . . . 14

Television Research . . . . . . . . . . 17

Multimedia and First Language Learners . . . . $\quad 18$

Cue Summation Theory . . . . . . . . 19

AV Input and Second Language Learners . . . . . 20

Summary . .

III METHOD . . . . . . . . . . . . . . 23

Subjects . . . . . . . . . . . . . . 23

Materials . . . . . . . . . . . . . 25

Instruments . . . . . . . . . . . . . . 25

Procedures . . . . . . . . . . . . . 27

IV RESULTS . . . . . . . . . . . . . . 31

Item Analysis Explained . . . . . . . . . . . . 32

Results of Item Analysis . . . . . . . . . . 35

Results of Two - Way ANOVA . . . . . . . . 40

Results of t-tests . . . . . . . . . . . 41 
V DISCUSSION . . . . . . . . . . . . . . . 46

Limitations . . . . . . . . . . . . . . 48

Future Research . . . . . . . . . . . . 49

REFERENCES . . . . . . . . . . . . . . . 52

APPENDIX A . . . . . . . . . . . . . . . 57

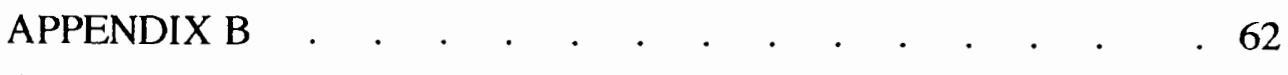

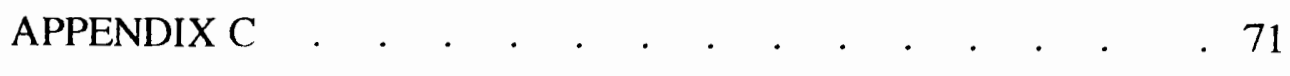

APPENDIX D 


\section{LIST OF TABLES}

TABLE

PAGE

I Primary Statistics for the Final Thirty-Item

Questionnaire . . . . . . . . . . . 40

II Results of Two - Way ANOVA . . . . . . . . . 41

III Case $2 \mathrm{t}$-test Comparing the Mean Scores of the Intermediate

Lecture and Intermediate Documentary Subjects . . . . 43

IV Case $2 \mathrm{t}$-test Comparing the Mean Scores of the Advanced

Lecture and Advanced Documentary Subjects . . . . 43

V Case $2 \mathrm{t}$-test Comparing the Mean Scores of the Intermediate

Lecture and Advanced Lecture Subjects . . . . . . . . 44

VI Case $2 \mathrm{t}$-test Comparing the Mean Scores of the Advanced

Documentary and Intermediate Documentary

Subjects . . . . . . . . . . . . . 45

VII Case $2 \mathrm{t}$-test Comparing the Mean Scores of All Lecture

Students Combined with All Documentary

Subjects Combined . . . . . . . . . . . . . . 45

VIII Difficulty Values of Each Question on the Original

45 - Item Questionnaire with All Scores

Combined . . . . . . . . . . . . 72

IX Reliability Analysis of the Original 45 - Item

Questionnaire with All Scores Combined . . . . . 73

X Reliability Alphas for Final 30 - Item Questionnaire

with All Scores Combined . . . . . . . . . . 74 


\section{LIST OF FIGURES}

1. Pie Chart of the Origins of the 94 Subjects . . . . . . 23

2. Population of the Four Cell Groups . . . . . . . . 29

3. Total Mean Scores of All Four Cell Groups on the

Original 45 - Item Questionnaire . . . . . . . 32

4. Difficulty Values of Questions 1 - 20 for Intermediate, Advanced, and All Subjects Combined . . . . . 35

5. Difficulty Values of Questions 21 - 45 for Intermediate, Advanced, and All Subjects Combined . . . . . 36

6. The Item - Total Covariance, Item - Total Correlation, and Total Difficulty Values for Questions $1-20$. . . 38

7. The Item - Total Covariance, Item - Total Correlation, and Total Difficulty Values for Questions 21 - 32 . . . 38

8. The Item - Total Covariance, Item - Total Correlation, and Total Difficulty Values for Questions 32 - 45 . . . 39

9. Response Patterns of the Advanced Lecture Group on the Original 45 - Item Questionnaire . . . . . . 58

10. Response Patterns of the Advanced Documentary

Group on the Original 45 - Item Questionnaire . . . . 59

11. Response Patterns of the Intermediate Lecture Group on the Original 45 - Item Questionnaire . . . . . . 60

12. Response Patterns of the Intermediate Documentary

Group on the Original 45 - Item Questionnaire . . . 61 


\section{CHAPTER I \\ INTRODUCTION}

This study investigates the use of video material as a means to develop the listening comprehension of students learning ESL. Certain theorists of language acquisition (Asher, 1969; Postovsky, 1981; Krashen, 1987) argue that there is a distinction between language that is learned explicitly and language that is acquired implicitly, or rather, unconsciously. As a result of this view of language acquisition, aural comprehension is given priority over speech production in the beginning stages of language learning. If indeed language is acquired through naturally-ordered stages, then the emphasis should be put on providing students with meaningful and authentic input and letting the language emerge in its own timing. Listening takes precedence over oral or written language production. Yet, recent reviews of research related to listening comprehension have concluded that listening is a skill that still has been greatly overlooked in research (Call, 1985; Long, 1989). At the same time, the advent of video technology is still relatively recent and, although video has been advocated as having great potential to be a useful tool of language teaching (Lonergan, 1984), it too requires more research in order to test its effectiveness in developing listening comprehension for second language learners.

There is indeed research in the use of audio and television presentations for educational purposes (Bagget \& Ehrenfencht, 1983; Barrow \& Westley, 1959; Hayes, Kelly, \& Mandel, 1986). Other research has focused on describing the results ofexperiments comparing audio, print, and pictures (Severin, 1967B). However, this research involved subjects who were tested in their first language. Research has only recently begun to apply theories of learning from electronic audiovisual input to second language learning.

What is essential in order to truly use video effectively in the ESL classroom is the development of a video pedagogy for second language learning. Motivated by this overarching need, this study attempts to incorporate theories of second language listening with theories of language comprehension that are based on the ability of listeners to make use of their existing world knowledge when attempting to comprehend linguistic input. 
Schema theory, in particular, has been advocated as a potential theory to explain both the nature of second language listening comprehension (Long, 1989) and, specifically, listening to video presentations (Altman, 1990). In addition, a variety of research investigating the impact of different audio visual stimuli upon memory will also be discussed in an attempt to develop a thorough pedagogy of video as a tool of ESL instruction.

Schema theory has emerged out of the field of cognitive psychology, which seeks to emphasize the interaction between humans' perceptions of the world and the manner in which cognitive structures sort through, categorize, and otherwise make sense of these perceptions. Meaning is believed not to exist in symbols and other stimuli; rather, meaning is provided by humans. Understanding the manner in which meaning emerges once stimuli are observed is a primary focus of cognitive psychology and schema theory. Schema theory has been applied extensively in research concerning reading strategies applied by second language learners (Carrell \& Eisterhold, 1983; Kitao, 1989; Rumelhart, 1980; Young, 1989). The present study will seek to apply schema theory to a discussion of using video to improve listening comprehension in the second language classroom.

\section{Theoretical Background}

Richards (1983) describes listening comprehension as a process whereby second language learners attempt to determine the propositional meaning of utterances. He describes a proposition as the basic unit of meaning of an utterance or speech act. Comprehending spoken discourse involves holding the initial input in short term memory, organizing it, grouping propositions to form a coherent message, and finally storing the propositional meanings in long-term memory and forgetting superfluous surface structure (Call, 1985). In order to determine a proposition's meaning, second language learners not only must have a degree of grammatical competence in the target language but they also must make use of "world" knowledge (Richards, 1983). Second language learners must certainly understand the effects of extra lingual factors, such as speaker intonation, body language and context, which affect meaning in comprehending the target language. Dunkel (1986) recommends that second language teachers use prelistening activities that "supply listeners with the social, cultural, or linguistic information they may lack, and yet need, to comprehend the content of the discourse" (102). 
For this reason, video presentations have been advocated as an effective medium in language teaching because they can be a source of extra lingual information (Lonergan, 1984). But MacWilliam (1986) claims that most of what has been written about using video in the language classroom has primarily been anecdotal. Little research has actually been done to test whether or not the video medium is an effective source of language input for the second language learner.

This study is grounded in schema theory, which stresses the role of a receiver's world knowledge in language comprehension. Schema theory has roots in psycholinguistics and theories of cognitive psychology. Schema theory emphasizes the interaction between listeners' perceptions of the world and their own existing knowledge structures (or schemata), which sort through, categorize, and otherwise make sense of these perceptions.

The term "schema" is attributed to Bartlett (1932), who assumed that memory was reconstructive rather than simply an act of recalling information verbatim. When a story, for example, is remembered, what is reconstructed is a mixture of what was read or heard and underlying knowledge which may be culturally specific. This "cultural schema" may not be present in a particular story but it still manages to be worked into the retelling of the story. For example, in one of his studies, Bartlett assumed that his subjects, who were British, had difficulty accurately recalling a folk tale from an unfamiliar North American Indian culture because the story's structure did not follow the typical pattern of European folk tales. In related research, Pritchard (1988) investigated whether or not the children from the United States and the Paula Islands would use different processing strategies when reading passages describing funeral rites in their respective countries. Subjects completed "think-aloud" protocols and retold each story after reading. Pritchard found that the children made quicker inferences reading about the funeral rite from their own culture. Both groups of children demonstrated poorer recollection of the story from the other culture. He concluded that "cultural" schema affected the choice of strategy employed by the subjects and their comprehension of a reading passage.

The role of schemata, or scripts, seems vital in not only the ability to recall stories, but also the ability to make inferences and make sense of ambiguous information. Bransford and Johnson (1973) conducted a number of tests to demonstrate the importance of context in comprehending ambiguous sentences and paragraphs. Their hypothesis was that the difficulty of learning new material correlated directly to a person's ability to generate relevant contextual information. They presented to groups of subjects an oral 
reading of an ambiguous paragraph that was actually describing a cartoon picture of a man serenading a women below her apartment window. Some groups were given no context before hearing the passage, others were shown a modified illustration and the remaining groups were shown the complete illustration before listening. As predicted, the groups which were given the complete visual context had superior recall of the passage. Bransford and Johnson argue that the complete illustration provided retrieval cues important in recall. They sum up their findings, saying,

The general pattern of these results indicates that subjects spontaneously make assumptions about extra-linguistic circumstances and draw on a wide range of prior knowledge in doing so. The subject's memory for a sentence or sets of sentences will therefore be a function of how he [sic] uses what he knows to interpret what he hears, and of how he uses this interpretation to modify what he already knows. (428)

Schema theory has a number of implications for second language learning. In particular, it can be assumed that much of the background knowledge that students bring to the ESL classroom is culturally specific. In addition, Altman (1990) suggests that learners of a second language whose grammatical competence is not developed enough will not be able to recognize even initial meanings of words when they hear audio input and, therefore, will slow down or even inhibit the use of any relevant background knowledge that they do have. In situations where the linguistic input is arriving through only one channel, such as through a radio, the listeners will have to create a context from the words that they hear. If all they hear is a string of unfamiliar sounds, it is unlikely that any "interpretation" will be invoked.

Altman (1990) suggests a five-part process of listening comprehension: decoding, schema postulation, schema expansion, modified decoding, and schema modification. Firstly, language is decoded. In other words, listeners' grammatical competence enables them to interpret and give meaning to the strings of sounds or written symbols that make up a discourse. As the language is decoded, it triggers, or engages, listeners' existing world knowledge (one or more schemata). The language essentially is related, in a broad way, to what listeners already know of the world. This preexisting knowledge not only provides a mental context for understanding, but it also guides interpretation of the linguistic material still to come. In a sense, the schemata modify the way in which the language to come is interpreted. However, the decoding process is still dynamic and can call for different schemata or modify the schemata that have already been recalled at any given moment. A cycle is therefore created whereby both language is decoded and schemata are modified 
indefinitely until the discourse or text is completed and understood. Carrel and Eisterhold (1983) have described this process as a combination of "bottom-up" and "top-down" processing, analogous to the more general schemata at the "top" working down to guide the interpretation of meaning which is coming "up" from written or spoken words.

The possible implication of Altman's theory is that beginning or intermediate ESL students whose vocabulary and grammatical competence suffer will be able to pick out the necessary meaning from aural input to set schemata, or "top-down" processing, into action. As demonstrated in Bransford and Johnson's (1973) research, the use of visuals can greatly remove ambiguity from otherwise ambiguous language. On the other hand, more advanced students who have greater vocabulary skills and grammatical competence may be able to pick enough meaning from the aural input to start generating interpretations. For them, if the input is not ambiguous, the use of visuals may end up being essentially superfluous. This apparently was the case in Mueller's (1980) study in which beginning German students who saw simple line drawings of characters while listening to a taped interview of German speakers scored higher on a seven-minute summary than beginning students who saw no visuals. However, when the task was repeated with advanced students, there was no difference between the visual and no-visual groups.

This study investigates whether or not the variety of photographic images provided by a documentary video will enhance this interaction between "bottom-up" and "top-down" processing for ESL students whose ability to interpret spoken English is at an intermediate level. It is not enough to simply assume that greater learning will occur if additional visual information is presented. The question, as it relates to second language listening comprehension, is whether or not the identical linguistic information of a soundtrack will be better comprehended with the aid of a number of relevant photographs that, theoretically, provide a richer visual schema. Rather than distract a listener from audio information, will relevant visual images enhance listening comprehension because the visual images are available to drive the conceptual processing that is essential to comprehension? If so, are certain visual cues more effective at stimulating this conceptual processing than others?

Two videos were created for the study. Both videos had the identical soundtrack; however Tape 1 (henceforth called the Lecture video) included only the image of a single speaker, standing at a lectern, reciting the narration as if giving a speech. Tape 2 (henceforth called the Documentary video) included video and photographic images which corresponded to the narration. Two pools of advanced and intermediate university-level 
ESL students were created. Approximately half of the students in each level viewed the documentary video while the other half viewed the lecture videotape. Therefore, at both levels, there was a "documentary" and a "lecture"group.

\section{STATEMENT OF HYPOTHESIS}

This study compares the test scores of groups of intermediate and advanced ESL students who viewed two different video tapes and completed a questionnaire of 45 "yes/no" questions based on the narration. One group of advanced and intermediate students viewed a video recording of a single lecturer giving a 10-minute speech. A second group of advanced and intermediate students heard the same speech, but saw video images that included "documentary" video footage of the people and places which the speech describes. Schema theory and psycholinguistic research argue that visual information can be effective in creating context for listeners and making otherwise ambiguous or incomprehensible input understandable. In comparing these two visual stimuli, Schema theory suggests that the visual images of the documentary video will provide more ongoing context for viewers, because they will be able to see the people and places which the lecture describes. The physical gestures of the lecturer will not provide as rich a supply of visual cues and this will, subsequently, leave the intermediate and advanced students dependent upon their knowledge of grammar and vocabulary to trigger the schemata necessary for them to understand the discourse. Advanced students may be able to decode enough from the aural input alone to comprehend the input. The question remains as to whether providing intermediate students with "visual schemata", which they could not otherwise generate due to their inefficient listening skills, will actually "jump-start" their decoding of a discourse and enhance their listening comprehension.

The hypothesis of the study is as follows:

The images contained on the documentary video will have a greater interaction effect upon the scores of intermediate - level adult ESL students who answer a true/false questionnaire while viewing the video than will the images contained on the lecture video. 


\section{CHAPTER II}

\section{REVIEW OF LITERATURE}

This section will discuss research from a number of disciplines in order to justify the use of schema theory as a viable theory explaining how visual stimuli can affect second language listening comprehension. The premise of schema theory will be discussed initially, including ESL research which has applied schema theory specifically to reading and listening comprehension. In addition, since schema theory has been strongly influenced by work in cognitive psychology and psycholinguistics, research from these disciplines will be discussed in order to show that it supports the basic premise of schema theory. Thirdly, research which has compared the effectiveness of using television and audio input to test first language listening comprehension will provide background for the few studies which have compared the effectiveness of different media in teaching second languages. Finally, a brief section will discuss research on audiovisual communication specifically concerning the neurological issues involved with receiving input from both visual and audio channels. In line with schema theory, the "cue summation" theory predicts that receiving input from both visual and audio channels will be superior to learning from one channel alone when the information in each channel is related.

\section{SCHEMA THEORY}

An important theme which has developed from cognitive psychology is that memory and comprehension are intimately joined (Schallert, 1982). For meaningful learning to occur, new concepts must be incorporated into an existing cognitive framework. In other words, the learner must be intent on relating new information to existing knowledge and that new material must be potentially meaningful. Material which is comprehended and understood is more likely to be remembered. The notion of "meaningful learning" is most notably advocated by Ausubel $(1963,1968)$.

Long (1989) suggests that schema theorycan better explain the nature of listening comprehension. Firstly, schema theorists argue that meaning does not reside in linguistic 
symbols, such as spoken or written words in isolation (Spiro, 1980; Carrel \& Eisterhold, 1983; Bransford \& Johnson, 1973, 1977). Rather, meaning must be provided by the person perceiving the stimuli (Niesser, 1976). Schema theory describes comprehension as a constructive act, whereby listeners analyze linguistic input and then relate that input to their existing knowledge of events, situations, attitudes, and other contexts (Pryluck, Teddlie, \& Sands, 1982). This knowledge, subsequently, acts as a context or guide to further interpretation of linguistic input. Thus, schemata organize what humans know about general classes of events, objects, and people (Anderson, 1980). Because second language learners do not have complete control of the linguistic code of the target language, they have difficulty recognizing and selecting the most pertinent input they hear. Long (1989) says that a schema-theoretical view of comprehension is analogous to a person matching jigsaw pieces to a photograph. A schema acts as a frame of reference for the organization of the linguistic input.

Schemata are not described as ready-made "files" of knowledge that are simply pulled out when a word reminds a person of something (Spiro, 1980). Humans could not have enough of these units stored for all of the new or novel situations that they will encounter in their lifetimes (Bower, Black, \& Turner, 1979; Mandler, 1984). Meaning, rather, is created as a result of the interaction between abstract knowledge and the clues that are available within a particular context, such as the words in a text (Schallert, 1982). The perceiver's schemata are changed and/or further created as a human perceives the world, or in this case, interprets a text. Cognitive development is a complex process of assimilating new input into existing knowledge and at the same time changing this existing knowledge in order to accommodate new or unfamiliar information. There is never a time when a human is without schemata (Neisser, 1976).

The term "schema", or the plural "schemata", (Bartlett, 1932) has been applied by researchers to describe a variety of aspects of cognitive processing. Anderson (1980) says that schemata are large bodies of knowledge that organize what a person knows about general categories of people, objects, and events while Neisser (1976) describes schemata as an active system of physiological processes. The important point about schemata is that they are an attempt to explain how humans' knowledge of the world acts as an existing context to which new information is compared, interpreted and organized. The schema is at once a structure of existing knowledge and at the same time is also a plan of action for future perceptions. "The result of this interaction is a particularized, concretized representation, a schema with its variables specifically defined..."(Schallert, 1982: 27). 
Although the examination of Schema theory is recent, the origin of Schema theory can be traced to the work of Bartlett (1932). Bartlett, who coined the term "schema", theorized that memory is a reconstructive act. In other words, people simply simply recall memories intact, like pulling files from a file cabinet, but rather memory is a reconstruction process which involves schematic knowledge that is not a part of the initial input. For example, Barlett assumed that people have "cultural schema" that would influence their recall of a story which was from a very different culture. In one study, English subjects read a centuries old story from Indians on the West Coast of Canada. In recalling the story, subjects systematically omitted or distorted facts and brought new information that was not in the story. Bartlett's conclusion was that when faced with a story which did not follow the same pattern of their own culture's folklore, these subjects unconsciously adjusted the story in order to make it fit their schema and hence, make sense of it.

Although arguably pioneering at the time, Bartlett's work was circumvented by the emergence of Behaviorism and the related Structuralist approach to language learning. At the time of Chomsky's (1959) critical challenge to Skinner's theory of verbal behavior, linguistics was dominated by a "structural" school which emphasized the study of verbal data that was overtly observable. Language behavior was viewed as a product of stimulus/response conditioning, rather than a product of deeper cognitive processes (H. Brown, 1987). It was thought that listening comprehension basically consisted of decoding phonemic, semantic, and syntactic segments of the target language. Words and sentences were spoken in isolation so that the learners could effectively discriminate between phonemic contrasts, word stress, and the intonation of sentences (G. Brown, 1987). Once a person could accurately discriminate between these segments of language, there really wasn't much more to say about listening comprehension.

Chomsky (1959) challenged the fundamental premises of Behaviorism, arguing that they could not adequately explain how children can quickly learn to create statements which are totally novel, or in other words, never before heard by them. Children demonstrate creativity with their first language which can't be explained solely by conditioning. Rather, he contended, humans are born with an innate disposition to learn language and children quickly discover the rules of their first language, enabling them to create utterances never before heard. His theory could be called "mentalist" in that it points away from conditioning and reinforcement and toward the contribution of the mental processes that humans bring to language development. Language was viewed as a process of hypothesis formation and the acquisition of rules rather than habit formation. In a similar shift, the 
tenets of Behaviorism were also challenged in the area of psychology as the field of Cognitive Psychology began to investigate the contribution of cognitive processes to learning, during the 1960s and 1970s.

\section{Schema Theory and Reading}

Much research examining the use of existing knowledge in interpretation has emphasized the interpretation of written texts (Mandler, 1984; Rumelhart, 1980; Adams, 1982). Rumelhart (1984) presents experiments where subjects were asked to read a passage line-by-line and report their developing interpretations of the text. For example, when presented with the sentence "I was brought into a large white room and my eyes began to blink because the bright light hurt them," nearly all of Rumelhart's subjects believed that this was either a scene involving an interrogation, in which the protagonist is a prisoner, or a hospital scene, in which the protagonist is a patient. The subjects typically reported that the words "white room", "bright light" and "was brought" were key in forming their hypotheses. How could these subjects come to such conclusions when neither of the words "interrogation" or "hospital" appears in the sentence? Schema theory suggests that these subjects had existing concepts about interrogations and hospital scenes which were invoked by the words in the sentences. The moment that the given words trigger a particular schema has been referred to as "instantiating a schema" (Rumelhart, 1980).

Once instantiated, schemata then work from the "top-down" to guide the analysis of information still to come. When a potential interpretation, or schema, is invoked, the reader will either continue to confirm that schema or discard it and look for another interpretation. For example, once a reader "instantiates" a HOSPITAL scene, that reader may anticipate the appearance of medical personnel in the text. If the sentence, "I was brought into a large white room and my eyes began to blink because the bright light hurt them," was followed immediately by the sentence, "Then the spotlight was turned off and I saw the audience politely waiting for me to make my speech," the instantiated HOSPITAL scene would either have to be modified or jettisoned in favor of some type of a schema that involves SPEAKER - AUDIENCE. Rumelhart concluded that subjects' interpretations were the results of inferences made into the text. These inferences involved material that was not addressed explicitly in the text. This points to the existence of information brought by the learner which is used to "fill in the holes" of the text. 


\section{THE DECODING PROCESS}

Schema theory suggests a five-part process of comprehension. Firstly, language is decoded. As the language is decoded, schemata are instantiated. The schemata then begin to guide the interpretation of the linguistic messages still to come. The schemata, in a sense, "impose" a context upon the text and modify the decoding which is still to come. Interpreting unfamiliar terms or expressions is greatly affected by this process. The learner will make guesses at unfamiliar information based upon the schema which has been invoked. Schemata, then, help to find meaning for ambiguous language. Finally, as in the HOSPITAL example above, just as schemata modify the decoding process, the instantiated schemata are also modified and adjusted by the continuing decoding process. These steps are repeated again and again until the input ends. Such a theory suggests that providing second language learners with a context will lessen ambiguity and thus, relieve the demands upon decoding .

An important clarification about schema theory is that it has been applied to a variety of actions, not reading comprehension alone. There are schemata related to spatial relationships and motor skills (Neisser, 1976), the stereotypical sequence of events (Schank \& Abelson, 1977), as well as categories of animals and objects (Anderson, 1980). In literature, the term "scripts" has often been used as synonymous with "schemata". However, Mandler (1984) suggests that a schema is a more general knowledge structure and a script is more concretely tied to a specific content. Both are still generic knowledge structures, but the difference may be akin to the difference between "eating dinner" and "eating dinner at a Chinese resaurant". The Chinese restaurant "script" would be more concrete in that it would consist of more specified sequences of actions. A schema, therefore, is hierarchically organized, with more general classes of events containing more specific classes of events embedded within them.

The primary role of schemata is in the construction of an interpretation of an object or situation or text. Rumelhart describes schemata as "a kind of informal, private, unarticulated theory about the nature of the events, objects, or situations we face" (Rumelhart, 1984: 3). Understanding of a text occurs when hypotheses generated by a schema (or set of schemata) provide a coherent interpretation of the various aspects of a text. Cognitive psychologists suggest that this process is the only means whereby meaningful learning can occur. Most notably among them, Ausubel $(1963,1967)$ explains that there is an important difference between meaningful learning and so called "rote" 
learning. This distinction may have implications for what constitutes "meaningful" listening, as well.

\section{Ausubel's Theory of Meaningful Learning}

Ausubel (1968) states that meaningful learning occurs when a new concept is related in a "nonarbitrary" manner to what the learner already knows. Rote learning, on the other hand, is purely arbitrary and does not result in meaningful learning because the learner does not have the prior knowledge needed in order to make the new concept meaningful. For example, if a native English speaker did not know that the English word "coiffure" refers to a male hairdresser, it would simply be a matter of rote learning to learn that the Spanish equivalent of "coiffure" is "peinado". An arbitrary association would be made between two words. However, if the learner makes an association between the word "peinado" and the concept of a male hairdresser, than that new information can potentially be made more meaningful because there is the existing concept of "male hairdresser" with which "peinado" can associate.

Ausubel (1968) claims that the two factors that make up meaningful learning are: 1) the nature of the material to be learned and 2) the nature of a particular learner's cognitive structure. Ausubel (1968) claims that new propositional meanings are "subsumed", or in other words "included within", the more general ideas in existing cognitive structure. Once "subsuming" ideas are established in cognitive structure, they can make other arbitrary facts potentially meaningful, provide cognitive stability for more new ideas, and organize related new facts around common themes, thus "integrating the elements of new knowledge with each other and the existing knowledge" (52). Ausubel's description of meaningful learning mirrors the theory that new information must be incorporated into existing schemata, though he does not use the terms "scripts" or "schemata". New ideas must not be arbitrarily related to cognitive structure, as occurs in random rote learning, or existing knowledge will not be useful.

Using similar language as Ausubel, Mayer (1975) outlines a three-stage model of internal processing which complements the assertions made by Schema theory. Mayer asserts that the main processing variables are 1) how much information is received, 2) how much prerequisite knowledge the learner has, and 3) what elements of the learner's existing knowledge are activated during learning and used to integrate the new material. The ThreeStage model assumes that a mental "learning set" is evoked at the start of learning and is used throughout the process to integrate new material. The idea of Mayer's "learning set" 
appears similar to the idea of "instantiating" schemata, in that a context which is either evoked or provided gives new information a place upon which to be attached.

\section{LISTENING COMPREHENSION}

The guiding concern of this study is evaluating how the use of visual cues affects E.S.L. students' comprehension of a documentary narrative. As discussed, schema theoryhas many different applications. It has been used to explain how readers make inferences (Rumelhart, 1980; 1984), how tennis players anticipate the flight of a ball (Neisser, 1976), and how people retell stories (Bartlett, 1932; Schank \& Abelson, 1977). The general principles of schema theory must be made specific to the act of listening. To do this, it would be helpful to see how compatible current listening research is with an emerging schema-theoretical approach.

Current research related to listening comprehension reflects the shift in second language learning theory toward both the importance of cognitive processes within learners and the influence of the contexts in which speech acts occur. Until recently, listening comprehension was the least researched skill of language learning (Brown, 1987). Listening was viewed as a passive act (Call, 1985). However, more recently, a surge of interest in listening comprehension has occurred recently. This interest is due to advocates of the "comprehension approach" to second language learning (Postovsky, 1981). The proponents of the comprehension approach argue that listening comprehension precedes production in all cases of language learning (Byrnes, 1984) and, therefore, should be the primary focus of language development, particularly in the early stages of acquisition.

Current research generally agrees that listening is not only an active process, rather than a passive one, but that linguistic knowledge is only one part of listening comprehension. Listening is treated as a very complex problem-solving activity (Byrnes, 1984). In addition to linguistic knowledge, listeners must also be able to utilize their existing world knowledge, such as the goal of the speaker, the context in which the statement is made (Richards, 1983), and the socio-cultural content of messages.

Researchers agree that the first stage of listening involves basically recognizing. spoken sounds. This undoubtedly requires some linguistic knowledge of the language being spoken. Rivers (1971) contends that listeners pass through an initial "recognition" stage where they begin to identify words and phrases from the new language. Nord (1981) describes this as the "semantic decoding phase" (74). There must be an initial association 
made between strings of sound and meaning. After the recognition stage comes the "selection" stage, where listeners actively sort out the crucial information from audio input which contains the "gist" of the message. In other words, the main propositions contained in speech are what the mind seeks out. The mind is concerned with meaning first, rather than remembering chunks of sound verbatim.

Clark and Clark (1977) offer a summary of the steps involved in listening. Listeners first receive speech input and hold it in short-term memory. They then try to organize what is heard into groups, or constituents, based on grammatical and semantic knowledge. Next these "groups" or sounds are identified and used to create the propositions that make up the message as a whole. Once the propositional message has been constructed, it is held in long term memory, while the verbatim form of the speech is forgotten. In addition to these steps, Nord (1981) claims that listeners utilize both linguistic schema and semantic schema as they analyze speech input. He emphasizes how listeners listen ahead or anticipate coming words, phrases, and sentences and then monitor their speech for error. This approach to listening comprehension treats listening comprehension as not only a matter of language processing, but also of reasoning.

\section{Psycholinguistic Research and Listening}

Psycholinguistic research examining the effects of visual images upon listening suggest that certain visual information can effectively improve the recall of aural input. A number of tests conducted by Bransford and Johnson (1973) explore the impact of visual cues on the listening comprehension of extremely ambiguous paragraphs. It can be argued that an ambiguously written paragraph will hamper bottom-up processing and thus make it difficult for a "schematization" to occur. In this study, subjects listened to the reading of a paragraph which was actually describing a cartoon drawing of a man playing a guitar and serenading a woman below her apartment window. All subjects were asked to recall as much of the passage as they could after hearing it. A Context-Before group saw the entire drawing and then heard the passage. The Partial-Context group saw a modified drawing in which the characters were arranged differently than the passage described. A Context-After group heard the passage and then was shown the drawing before being tested. Finally, two "No- Context" groups only heard the paragraph, being shown no drawing.

Bransford and Johnson $(1973,1977)$ predicted that the subjects who received appropriate prior knowledge would be able to comprehend the passage without difficulty and would also be able to recall the passage better then groups who were given no such 
prerequisite knowledge. The comprehension and recall levels were indeed the greatest for the Context-Before group. Although subjects in the Partial-Context group had elements of the drawing available to them while listening, their comprehension and recall were significantly lower than the Context-Before Group, but were higher than the Context-After and No-Context groups. This suggests that having prior knowledge alone does not insure that knowledge will be useful during comprehension. Bransford and Johnson (1973) argue that the passage communicates a particular "semantic context" which only the complete drawing captures. This "semantic context" is key to comprehension. The fact that the Context-After group had difficulty comprehending and recalling the passage also suggests that if difficult-to-understand audio input comes first and is followed by visual information, the visual information is less effective in helping comprehension retroactively.

Paivio (1975) argues that if a taxonomy were created which ranged from items most likely to be recalled to the least likely, concrete objects and pictures would have the greatest probability of being recalled, followed by words describing concrete objects and finally words which represent abstract concepts. Baggett and Ehrehfencht (1983) conclude that audio input can associate well with visuals that were presented previously. In contrast, if audio input comes first and is then followed by visual information, the visuals do not create good associations with the audio input presented previously. In other words, audio can help learners remember what they saw, but a visual image does not effectively cause learners to recall what they heard. Apparently, visual information is more readily retained so that when audio information comes later, the subject can still make associations between the two channels. Audio comprehension, on the other hand, seems to deteriorate more rapidly than visual comprehension (Travers, 1964).

Salomon (1974) theorizes that visual media, in particular, serve the function of "concretization". Learners need to generate mental images of events which complement verbal information; otherwise, that same verbal information will remain abstract and comprehension will be limited. Visual images "assist the learner by formulating a spatial or visual representation that he [sic] is incapable of generating on his own" (Salomon, 1974: 400). Once these visual"codes" are internalized, they can become "schematized", or in other words, detached from their original context, and can then be applied to completely new instances.

Bransford and Johnson's conclusions are supported by Arnold and Brooks' (1976) study, which also presented subjects with one drawing where characters are interacting in a scene and another drawing where the same characters are randomly placed and are not 
interacting. Arnold and Brooks (1976) supported the hypothesis that the difficulty of learning new material correlates directly to a person's ability to generate relevant contextual information. These results also indicate the potential power of visual information to help interpret linguistic input. Not only did the photo offer cues that the subjects could refer to, but it can be argued that the photograph "directed" the interpretation of the linguistic input.

What implications does the current discussion about different visuals have for second language listening comprehension? Listening alone involves a one-channel medium (Altman,1990) . Without visual cues or prior knowledge instantiated, all of the cues available to the second language listener exist in only one channel. If a listener is lacking in grammatical competence, there is a breakdown in the decoding process and "schematization" is hampered, resulting in poor comprehension. This was apparently the case with the no-context group in Branford and Johnson's (1973) study. This suggests the powerful influence of visual "advance organizers" which are already internalized and activated, ready to begin modifying the decoding process from step-one. The potential of video lies in its ability to provide a constant stream of visual assistance for the process of schematization. Schematization will then be brought about through a combination of imagery and the target language. "The video image thus serves as a sort of catalyst, accelerating the schematizing process at the very point in their development when students are most in need of that acceleration" (Altman, 1990: 12).

The approach to listening comprehension that emphasizes the listener's semantic and schematic knowledge complements well psycholinguistic research concerning the use of visual context to enhance listening comprehension. Seeing a picture can allow a listener to anticipate coming information to the extent that comprehension is relatively effortless. But, as the Bransford and Johnson studies indicated, the semantic content of visual images can affect the level of comprehension. The group that saw a modified picture did not recall the story as well as the group that saw the compete picture prior to hearing the narrative. Schema theory seems compatible with current listening research. The next two sections will discuss how well schema theory complements research which has specifically studied learning from television and various multimedia, respectively. It is not enough to simply say that visuals can help to make ambiguous language more clear. The nature of the visuals must also be taken into consideration before we can reach a potential theory for the use of video to develop listening comprehension. 


\section{TELEVISION RESEARCH}

Media are composed of three major components: symbol systems, messages, and technology of transmission (Salomon,1974). Of these three, the symbol system is most important because it is what activates the specific mental processes used to extract and process information. When comparing the effects of different media on learning, the focus should be on the "symbol system" unique to each medium, rather than simply be a comparison of technologies. If a media "codes" information in a unique manner, it can be expected that unique mental processes will also be activated.

Research investigating the effects of television and radio on children's comprehension indicates that in verbal recounting of stories, children who view televised stories more frequently refer to visual content in making inferences related to the story, such as the qualities of characters and explanation of their movements. Children who hear the same story via radio are more likely to draw upon information not present in the story. For children learning in their first language, radio stimulates the use of personal world knowledge for inferring, whereas television augments knowledge of visual details, picture sequencing, and inferences based on actions (Beagles-Roos \& Gat, 1983; Hayes, 1986). Thus, when only listening, the children seem more likely to "fall back" upon their own knowledge and imaginations in order to comprehend and subsequently recall the story. The children who watched television were not as likely to draw upon information that was not present among the visuals. The visuals may actually have inhibited the use of schemata that would otherwise be triggered by the audio channel alone. The visuals certainly function like schemata, but in so doing, may indeed prevent the instantiation of other schemata.

Hayes (1986) investigated two errors in the recall of stories, namely the addition of erroneous events or characters and distortions of events. He wanted to find out whether or not these errors occur more frequently for aural or aural/visual presentations of stories. $\mathrm{He}$ concluded that children who heard only auditory versions distorted information and had more difficulty remembering features of the plot, but showed a greater retention of dialogue than children who viewed a televised version of the story.

Greenfield and Beagles-Roos (1988) compared the responses of children from different socio-economic class and ethnic groups to aural and televised versions of a story. In the first test, part of the story was presented and children were asked to predict the ending. The aural groups created more original material while the television groups had a 
greater production of words repeating the story. In the second test, the story was presented in its entirety and children were asked questions to test recall and inferencing. For all the groups, television enhanced overall retention of the story, whereas radio enhanced the recall of direct dialogue. The authors recommend that audio be used to stimulate imagination and highlight verbal information and that video be used to transmit information in general and action in particular. Drew and Reese (1980) concluded that children, regardless of age, will remember more from a newscast with film than without such visuals, as demontrated through aided and unaided recalls. In other studies, which used adult subjects, it was found that those who viewed television news stories scored either significantly higher or somewhat higher on tests of immediate recall than those who listened to radio (Barrow \& Westley, 1959; Gunter, Furnham, \& Gietson, 1984; Nasser \& McEwen, 1976). The general conclusion from research comparing learning from television and radio is that visuals may in fact shape the recalling of a televised story more than audio input alone. These conclusions regarding learning from television are also reflected in research concerning the use of other forms of visual media.

\section{MULTIMEDIA AND FIRST LANGUAGE LEARNERS}

A Schema-theoretical explanation of learning from television generally agrees with related research regarding multiple channel communication and whether combining the pictorial channel (non-verbal) and the auditory (verbal) channel make for more effective learning than learning from either channel alone. This research has tended to emphasize physiological and neurophysiological aspects of communication processing. Hartman (1961) presents an extensive review of current literature and concludes that research is inconsistent if not contradictory. A difficulty in examining the literature arises from the fact that the conclusion as to whether visual or auditory presentations are superior apparently depends greatly upon the conditions of specific experiments. Severin (1967a) concludes that the lack of agreement of research is due to a number of causes: there is a misunderstanding of the interference between channels; material is presented by two channels but testing is done by only one channel; the capacity of the central nervous system to process information is undefined; and the question of what makes a particular cue relevant to learning is not specified. 


\section{Cue Summation Theory}

Hsia (1971) compares the processing of audio/visual (AV) information to electronic signals passing through a wired circuit. Some signals are amplified, while other signals are filtered, condensed, modified, or stabilized (Hsia, 1971: 64). Hsia (1971) concludes that so long as input is not in excess of the capacity of the central nervous system, AV information probably communicates more effectively than $\mathrm{A}$ or $\mathrm{V}$ alone. This premise forms the basis of theory in audiovisual communication called the "cue summation theory" (Severin, 1967a). This theory predicts that leaming increases as the number of available audiovisual cues in a stimulus is increased. In other words, the total "sum" of the combined cues of words and related visuals, for example, will provide for greater input than either channel alone (Hartman, 1961; Anderson, 1972). The key qualification, however, is that the cues be related. Hsia (1968) cautions that before generalizations can be made about the degree of learning that occurs, conditions at the time of input must be carefully specified. The information in the A and $\mathrm{V}$ channels can be redundant (presenting the same information), related, unrelated, or contradictory. Unrelated or contradictory cues are predicted to cause interference. If there is an "overload" of AV information, one of the channels will suffer as the brain filters out excess information.

Severin (1967b) tested the cue summation theory by presentation of a series of names of natural objects to six different groups of subjects: audio + related pictures, audio + print, print alone, audio + unrelated pictures of the same class of objects, and audio + pictures of unrelated pictures of a different class of objects. As predicted, the audio + related picture group outperformed all other groups on recall tests while the last audio + unrelated group did the worst. Multiple-channel comprehension appears to be superior to single-channel comprehension when relevant cues are "summated" and thus "reinforced". Learning is inferior when irrelevant cues cause interference between the channels. Travers (1964) found that when certain devices draw attention to one of the channels in particular, subjects' abilities to learn from the other channel are inhibited. Anderson (1972) recommends that crucial information be provided in the audio channel and video imagery be "bare-bones" so as to prevent irrelevant cues from interfering. Reese (1984) found that rearranging the editing of an English-language news story affected the recall of Englishspeaking adults. Although the same total scenes were shown to both groups, one saw a version which was edited so that the audio description and video images were redundant. The other saw a version where the visuals were rearranged so as not to be synchronized 
with the audio. The group viewing the redundant version scored better on a comprehension test.

If the cue summation theory is valid, it may be valid only to a certain point, beyond which the central nervous system is overwhelmed. There is also the question of what makes a cue redundant and/or relevant. Severin (1967b) admits that although there is support for the cue summation theory, it is also possible for researchers to make erroneous assumptions about what subjects will think are relevant cues or not. The general conclusion from research into multichannel communication is that humans likely can learn more from audiovisual presentations than those of a single channel, as long as relevant cues exist between the channels.

\section{AV INPUT AND SECOND LANGUAGE LEARNERS}

Although there is still little research regarding the use of video in second language listening comprehension, much of the research that does exist supports Altman's hypotheses. Tyson (1989) tested the recall of an audio-only and an audio-visual group of university-level ESL students watching a documentary about wine-making. Tyson (1989) predicted that visuals would distract students and, subsequently, inhibit their processing of the verbal narration. However, based on free recalls written in English, the video group recalled more "idea units" than the audio-only group.

Mueller (1980) tested to see if simple line drawings of characters engaged in conversation would assist beginning German students in comprehending a taped interview of native German speakers. The line drawings were intended only to show the participants of the interview and their relationship to one another, information that could also be obtained from the dialogue alone. There was a visual-before, a visual-after, and a novisual group. Both visual groups scored higher on a seven-minute summary after listening than the group that saw no line drawing. However, the experiment was repeated with more advanced German students and there was no significant difference among the three groups. Mueller concludes that the effects of visuals correlate closely to the proficiency level of the students. Advanced students were able to gain enough information from the audio cues alone, thus making the visuals superfluous. However, Parry and Meredith (1984) found that first, second, and third year Spanish students who saw and heard dialogs between native Spanish speakers scored higher on a multiple choice test than the same proficiency groups who only heard the dialog. The visuals affected all three proficiency levels. 
Not all research supports the theory that video will enhance listening comprehension. Ortmeyer and Goldstein (1980) gave 112 first year ESL students a listening test two weeks before the presentation of an audio and audio-visual version of a short documentary. Upon viewing or listening to the presentation, the subjects were tested for recall and the ability to search for factual information. The results of the recall of the documentary were then compared to the subjects' individual scores on the prior listening test. As predicted, the students with the low, middle, and high scores on the prior listening test also scored in the low, middle, and high ranges on the recall test. Ortmeyer and Goldstein concluded that since there was a greater correlation between the audio groups' recall and listening test scores, the audio mode was more effective. However, there remains some question as to whether the testing method did not somehow favor the audio group.

The effects that visuals have on second language listening comprehension appear to be both potentially positive and negative. Visuals can enhance listening comprehension as long as they are relevant to the audio input. This presents the need for future research to better define what makes a visual cue relevant or not. Schema theory suggests that visual cues will indeed enhance the processing of linguistic audio input. In the case of the Bransford and Johnson (1973) test, there was no group that was simply shown the drawing and asked to interpret it. Had this information been added, it may have given insight into the nature of the hypotheses that the subjects were forming about the drawing before listening to the audio passage. Apparently, whatever the nature of the hypothesis testing, seeing the complete drawing prior to listening significantly improved subjects' ability to construct the semantic meaning of the passage. Hearing the passage first then seeing the complete drawing did not have the same result.

\section{SUMMARY}

The schema theory is a viable theory for advocating the use of video material to develop the listening comprehension of ESL students, particularly in the early stages of their English development. Research regarding reading comprehension demonstrates that readers use their own background knowledge in order to infer the meaning of written material. By the same token, when provided a visual context prior to listening to ambiguous language, listeners can make associations between what they see and hear, and can comprehend the ambiguous story more easily, unlike other listeners who lack such a 
visual context. This research speaks to the powerful effect that a listeners' ability to place linguistic input within a context has upon listening comprehension. When a listener lacks the grammatical competence to decode words well enough to create interpretation or is faced with ambiguous input, visuals can act to guide the comprehension. However, research comparing the impact of different visual input upon listening comprehension also shows that certain visual information can be a greater help than other information. Irrelevant visuals may actually cause interference and inhibit listening comprehension. Therefore, the study reported here attempts to compare two types of visuals upon the comprehension of the same audio information to see if either enhances comprehension. 


\section{CHAPTER III}

\section{METHOD}

\section{SUBJECTS}

This study was conducted during a summer term at Portland State University (PSU) and the University of Oregon ( $\mathrm{U}$ of $\mathrm{O}$ ) and involved ninety-three upper and lower intermediate adult ESL students. Thirty-nine advanced and twenty-three intermediate students were enrolled at the intensive English language program the American English Institute (AEI) at the $\mathrm{U}$ of $\mathrm{O}$. A total of six intermediate students were enrolled in the regular ESL program at Portland State University. The remaining 26 subjects were members of a group from a Japanese school (henceforth referred to as the "Independent Group") who were taking part in an ESL program, conducted on the campus of PSU, which was separate from the usual ESL program at PSU. These students came as a group to the United States and were not placed into levels as they would have been had they been enrolled in either of the regular programs at PSU or the AEI.

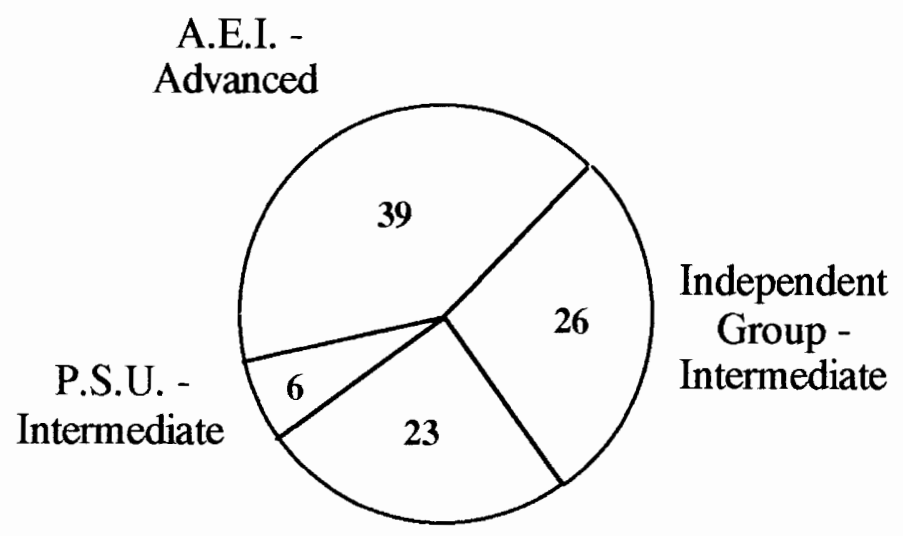

A.E.I. -

Intermediate

Figure 1. The origins of all 93 subjects. 
The subjects at PSU and the AEI were placed in their language proficiency levels by their respective ESL departments, based either upon their individual scores on standardized placement tests conducted at the beginning of each term or upon the discretion of faculty at each school. Rather than seek permission to check the individual test scores of subjects at these two schools, the researcher assumed that the students had been accurately placed in their proficiency levels. The AEI grouped its students into six proficiency levels whereas students at PSU were grouped into four levels. The ESL departments at each school provided their respective placement criteria, based on standardized test scores, which were used to place their students into levels. The Michigan Test for English Language Proficiency (Converted) was the sole proficiency test common to all ninety-three subjects. For example, "level 5" students at the U of O were those students whose most recent score on the Michigan Test was between 64 and 71; whereas students at PSU who most recently scored between 65 and 75 on the Michigan Test were considered "level 3" students. In order to place students from each school into an "advanced" group for this study, the two score ranges were combined to create a score of 64 - 75 on the Michigan Test as the definition of the "advanced" group for the study.

Subjects for the intermediate group were taken from PSU, the AEI, and Independent Group. The AEI used a Michigan score of between 48 - 55 as the range for its "level 3" students. The researcher was given access to the individual Michigan scores of students in the Independent Group because a standard placement range had not been created for its students. The researcher reviewed the Michigan Test scores of each subject from the Independent Group prior to testing. The scores ranged from a high of 61 to a low of 41 . The researcher desired to have a reasonably large sampling from this group and, therefore, chose $44-56$ to be the scoring range of the study's intermediate group. Given that a difference in comprehension was predicted at the lower proficiency level, it was decided that if the AEI range of 48 - 55 were to be broadened, it would be better to broaden it in the direction of the lower score. The answers of three students from the Independent Group who had scored 41, 57 and 61, respectively, on the Michigan were thrown out.

Originally, 102 subjects participated in the study. In addition to the three subjects from the Independent Group just mentioned, six other test questionnaires were discarded for a number of reasons: two subjects were from Latin American countries and spoke with the researcher after the testing period of their familiarity with Costa Rica, one subject slept during the video presentation, two individuals arrived late, after the test had already begun, and finally, one subject did not sign the consent form. 


\section{MATERIALS}

The video material for this study was created by the researcher. A narration was written based upon experiences that the researcher had as a student of Spanish in Costa Rica. The narration discussed general historical descriptions of the country as well as detailed descriptions of events which the researcher attended while in Costa Rica (see Appendix B). The researcher was an amateur videographer and personally recorded scenes from daily life in Costa Rica, both in large cities and remote villages with a camcorder. The narration was based upon this video footage. This content was chosen because the researcher could maintain control of the content of the narrative, the pacing of the narrator's voice, and the editing of the video footage. Thus, creating original video material was seen as most convenient and suitable for the study. It was also assumed that a video about Costa Rica would be novel for the subjects taking part in the study.

Two separate video tapes were created. The first video tape was a video recording of the researcher standing at a lectern in a television studio reciting the narration, as if giving a speech to an unseen audience. There were no props or backdrops to give any indication that the speech was about Costa Rica nor were there any cut-aways or edits. A simple waist-to-head shot of the researcher speaking was the only visual content of the first tape. The speech lasted approximately ten minutes.

Next, on a second video tape, the video footage of Costa Rica was edited so as to follow the narrative. Some still photographs were incorporated into the video when no suitable video footage was available to support a particular fact in the narrative. Therefore, the visuals of the second video tape were a combination of motion picture and still pictures. Once the second video was edited, the exact soundtrack of the first video tape was dubbed onto the second videotape. Therefore, two videotapes were created, each with the identical soundtrack but with different visual content. Henceforth, the first video tape will be referred to as the "lecture tape" and the second videotape as the "documentary tape".

\section{INSTRUMENTS}

Listening involves a number of skills, and measurement of listening must specify which skill (if not all) involved in listening comprehension will be the focus. Chastain (1979) cautions that tests should not go beyond the point of students indicating that they understood what they heard. With this in mind, a questionnaire of 45 questions was 
written based directly upon the narration (see Appendix B). The questions were written in a form which would allow the subjects to answer "yes" or "no". A binary test such as this was chosen because it was assumed that students could answer the questions more quickly then a multiple choice questionnaire, thus allowing for a greater number of questions to be answered in the limited testing time.

In creating a yes/no questionnaire, the researcher attempted to construct questions which either agreed directly with a statement made in the narration or which directly contradicted a statement in the narration. Questions, whether requiring a no or yes response, were phrased in two ways. Some questions were phrased in a way that they nearly replicated the narration verbatim. The questions of this type that required a negative response had a key word changed so as to make the question disagree with the narration. For example, question eight asks, "Do Costa Ricans have elections every six years?" The place in the narration describing elections in Costa Rica states, "Ever since then (the civil war in 1948), Costa Ricans have enjoyed free and peaceful democratic elections every four years." A student could listen for the words "elections every years" and listen specifically for a change in the number from six to four.

The second type of contradictory question did not mirror the exact wording of the narration, asking instead a question that would force the subject to understand a proposition made in the narration and then evaluate the logic of the question based upon that broader proposition. For example, question six asks, "Does Costa Rica have a large army?" The narration describes how in Costa Rica "there is no military of any kind" and that Costa Rica "has no army of any kind." To answer this question correctly, subjects could not simply follow the narration and recognize the changing of a key word. The subjects, assuming that they understood the vocabulary of the sentence, would also have to understand that since Costa Rica has no army, having a large army would not be logically possible.

Questions which required a "yes" response were also either worded similarly to the narration or agreed with a proposition made in the narration. For example, question thirtyone asks, "Do villagers in Sabanias work on coffee farms?" The narration states, "The people who live in Sabanias generally work on coffee farms and on large plantations that grow sugar cane" while the documentary visuals show a tractor driving down the street of a small county village (see Appendex B to read the script and the accompanying visuals). Subjects could essentially listen to the narration and compare the wording of the question to the statement in the narration. However, Question 22 states, "Did Los Guidos have electricity or clean water in 1990?" The narration states, "And Los Guidos did not have 
electricity or running water until 1988." The documentary visuals show a small boy with a soiled face standing on the side of a dirt road. To evaluate whether the village had electricity in 1990, the subjects would first have to understand that electricity and water were brought in 1988 and assume that both were still provided in 1990. This was expected to be a more difficult type of question to answer than one where only one key word was changed.

The questionnaire was essentially a combination of a selective listening test and a test of comprehension. Subjects were intended to read the printed questions, hear the questions read aloud by the researcher, and then answer the questions as they watched the video tape play on the television. Giving the subjects the printed questions prior to testing was intended to prepare them to listen for specific information in the narrative and accurately demonstrate their understanding as soon after the moment a proposition was comprehended as possible.

An admitted limitation of the questionnaire was that it was not tested in a pilot study prior to being used to test the ninety-four subjects in the current study. The researcher failed to allow appropriate time for a pilot study between the final editing of the video tapes and the scheduled testing times at the AEI, where the first testing took place. The AEI only allowed the researcher to test for two days during the first week of the summer session. Because of the large number of subjects provided by the AEI, eventually totalling sixtyone, the researcher chose to risk using an untested questionnaire, rather than treat all sixtyone subjects as a pilot study. Due to the lack of a pilot study, an item analysis was later conducted for each question after testing was completed, to judge whether any questions would have to be removed, as if a pilot study had been done in the first place. This resulted in the exclusion of ten of the forty-five questions on the questionnaire. The remaining 35 questions were then examined. The results of this statistical analysis will be discussed in chapter four.

\section{PROCEDURES}

The testing times for all of the subjects took place during normally scheduled class times, which meant that only 50 minutes were permitted at the AEI and PSU, including the explanation of the study and completion of consent forms. Subjects were told that in addition to taking part in a research project the listening activity would give them practice at listening to either a lecture or a documentary, depending upon which tape they were to 
watch. All ninety-three subjects were given identical questionnaires prior to watching either the documentary or lecture video tape. Subjects were asked not to read the questions during the first viewing, but instead to pay attention to the video on the television screen. While most students complied with these instructions, approximately ten percent of students in each cell group did look through the questions during part of the first viewing of their respective tape. If subjects were seen reading the questions during the first playing of the tape, the researcher did not attempt to intervene for fear of distracting other viewers and thus creating an inconsistent testing environment.

The narration was divided into four distinct sections, each varying between two and four minutes. On the lecture tape, sections were signalled by a brief pause in the voice of the speaker and a change of subject. In the documentary video, there was a brief black screen between sections two and three, but otherwise, the sections were simply signalled by a change in subject matter on the screen and the same pause in the voice of the narrator.

The questionnaire was also divided into four sections corresponding to the sections in the videotapes (see Appendix D). Once the tape had been viewed without interruption it was stopped and rewound. At the AEI, a large screen television, measuring approximately 36 inches in diameter, was used to show both videos. At PSU, the videos were shown on a television screen measuring 24 inches.

Seven testing times were conducted: four at the AEI and three at PSU. The largest number of students tested at any one time at the AEI was nineteen and the smallest was thirteen. The largest number of students tested at any one time at PSU was seventeen and the smallest was six. In every testing situation, care was taken to make sure all subjects could see the screen and that the volume was loud enough for students at the back of the room to hear clearly.

After viewing the tape a first time, subjects were asked to look at the first page of questions. The researcher read the questions in the first section aloud while subjects read along silently. The subjects were then told that the reading of the questions was intended to prepare them to listen for specific information in the narration. Subjects were instructed not to answer any questions until the video tape was actually playing. Once the first section of questions was read, the researcher replayed the tape from the beginning and subjects answered the questions as the tape played. The video was paused at the end of section one and subjects were then given thirty seconds to review their answers. Subjects were instructed to answer every question in each section. The same method was used for the remaining sections. 
Of the intermediate group, twenty-three watched the lecture video and thirty-one watched the documentary video. Of the advanced group, twenty-one viewed the lecture video and eighteen viewed the documentary tape. Therefore, as seen in Figure 2, four cell groups were created: 1) Advanced - Documentary, 2) Advanced - Lecture ,3) Intermediate - Documentary, and 4) Intermediate - Lecture.

Correct questions were considered those where the subject either circled, underlined, or checked the correct "yes" or "no" response. Questions were considered incorrect if the subject marked the wrong response, marked both "yes" and "no", or failed to mark either "yes" or "no". The scores of each test were simply the total of the correctly answered questions.

\begin{tabular}{|c|c|}
\hline $\begin{array}{l}\text { Advanced } \\
\text { Lecture } \\
\text { Group } \\
\text { (Tape 1) }\end{array}$ & $\begin{array}{l}\text { Advanced } \\
\text { Documentary } \\
\text { Group } \\
\text { (Tape 2) }\end{array}$ \\
\hline 18 Subjects & 21 Subjects \\
\hline $\begin{array}{l}\text { Intermediate } \\
\text { Lecture } \\
\text { Group }\end{array}$ & $\begin{array}{l}\text { Intermediate } \\
\text { Documentary } \\
\text { Group }\end{array}$ \\
\hline (Tape 1) & (Tape 2) \\
\hline 24 Subjects & 31 Subjects \\
\hline
\end{tabular}

Figure 2. The four cell groups.

The challenge to designing any test is creating it so that it accurately tests the skills that it sets out to test. In terms of Schema theory, there are a plethora of variables that will affect the subjects' ability to complete the questionnaire: any prior knowledge of the content that the students may have, their degree of familiarity with "yes/no" questions, the relevancy of the visuals in both videos, and the schema that may be instantiated by reading the questions prior to viewing. Certainly, as well, the wording of particular questions also comes into play. 
These concerns aside, three statistical steps were taken to analyze the results of the questionnaires. Firstly a series of calculations were done in order to validate the questionnaire itself. The nature of these calculations will be discussed in further detail in chapter four. Based upon a final battery of 30 questions, a 2-way ANOVA was conducted to test for an interaction effect. Finally, a series of t-tests was also calculated in order to examine the differences in mean scores between specific cell groups. 


\section{CHAPTER IV}

\section{RESULTS}

Two primary procedures were conducted with the data from all four cell groups. Because the questionnaire had not been pretested in a pilot study, the validation of the question items themselves was required before reliable scores of the cell groups could be compared. Had the initial data been that of a pilot study, the eventual questionnaire used in the test may have been different than the forty-five word questionnaire that the subjects answered. As a result, the first set of analyses done was intended to weed out questions that appeared too easy or difficult and/or did not contribute sufficiently to the overall variance of the test. The criteria for omitting questions will be discussed in more detail below. Once undesirable questions were omitted, a final battery of 30 questions remained. Had a pilot study been done, these 30 questions would have been the final questions presented to the groups. This procedure was essentially a statistical pilot study done "after the fact". The mean scores of the groups within each level were then recalculated based on the revised 30 - item questionnaire and then compared, using both a 2-way ANOVA and a number of t-tests. A discussion of the item-analysis procedure will occur first, followed by the results of the ANOVA and t-test calculations.

The hypothesis of the study was stated as follows:

The images contained on the documentary video will have a greater interaction effect upon the scores of intermediate - level adult ESL students who answer a true/false questionnaire while viewing the video than will the images contained on the lecture video.

The mean scores of the intermediate subjects appear in figure 3 . The scores reveal a clear division between the proficiency levels, although it appears also that the test was not particularly difficult for the intermediate groups. Of the advanced subjects, the mean scores were 38.9 for the lecture group and 37.8 for the documentary group. Of the intermediate subjects, the mean scores were 33 for the lecture group and 32.5 for the documentary group. Therefore, there were only slight differences in the mean scores between the groups within each proficiency level. 


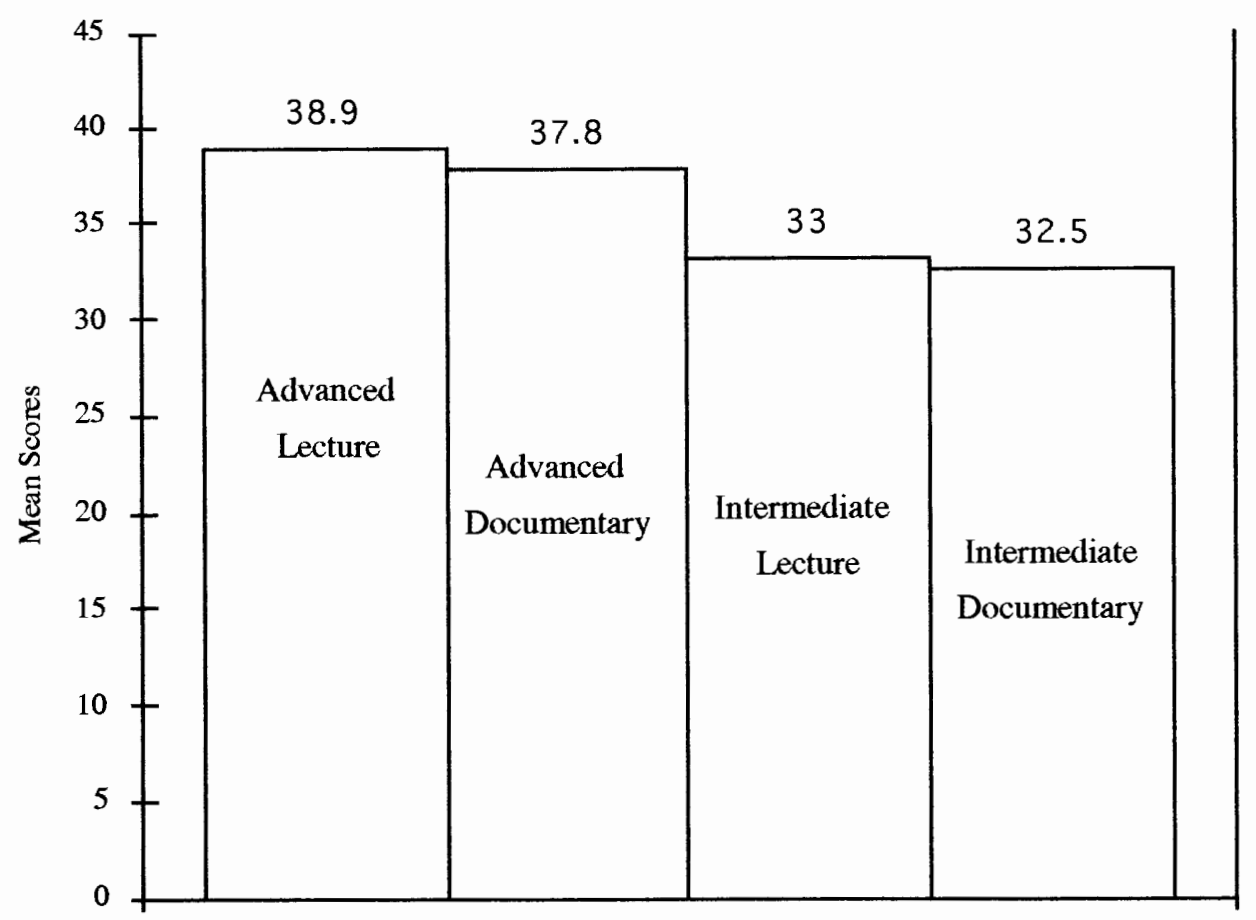

Figure 3. The total mean scores of all four cell groups on the original 45 - item questionnaire.

Though at first glance there appears to be a visible distinction between the proficiency groups based on total mean scores, much more analysis of the individual questions was required before any conclusions could be determined with accuracy. A number of criteria were used to determine which questions were worth keeping in the study and which questions would not suitably reveal differences between subjects.

\section{ITEM ANALYSIS}

According to Ferguson (1981), the purpose of a test such as the one used in this study is to distinguish between individual test takers. A question, for example, which is answered by either $100 \%$ or $0 \%$ of test takers doesn't demonstrate any variation among those taking the test. Popham (1990) states that if a test's questions are relatively homogeneous in nature, they should then essentially test the same skill or knowledge and subsequently reveal differences that exist among the subjects taking the test. In other words, if the difficulty levels of the questions are consistent, then an examinee with strong language profinciency, in this case, should gain high scores "across the board" while a 
student with less language profienciency should also score poorly "across the board". There are a number of approaches that were taken to analyze the degree of variance and homogenity that were present among the questions.

Both the standard deviation and the variance are measurements whereby one can judge the amount to which all scores in a particular distribution vary from the mean, or average score, of that same distribution. Both the variance and the standard deviation indicate how far all scores in a given distribution "typically" vary from the mean (Sprinthall, 1990: p. 43). Just as the mean represents an "average score", the variance and standard deviations represent an "average" deviation. Firstly the variance is calculated. The standard deviation is simply the square root of this variance.

A large variance and/or standard deviation indicates that there is a sizable spread in the distribution. In other words, many of the scores are deviating broadly from the mean. A small variance or standard deviation indicates that scores are similarly clustered around the mean. Conceptually, standard deviation and variance are equivalent, although mathematically there are cases where it is more suitable to work with the variance than the standard deviation and vice versa. Ferguson (1981) asserts that test makers attempt to ensure that test items have sizable variances in relation to the number of items on a given test. One calculation which reveals this is the level of inter-item covariance. An item with a large inter-item covariance contributes more to the overall variance of the test, and, subsequently, reveals a greater difference among test takers.

The goal of the item analysis was to ensure that the questions were consistent in their difficulty while at the same time contributing to the overall variance of the test. An additional calculation used was intended to evaluate the degree of internal consistency, or homogeneity, that existed among the items. Popham discusses internal consistency as one type of reliability. Cronbach's coefficient alpha $\alpha$ was used to measure the reliability of the initial 45 - item questionnaire. Cronbach's calculation involves the variance of the total test, the sum of the variances of individual items, and the number of items on the test. The resulting $\alpha$ number represents the "internal-consistency form of reliability" (Popham, 1990: 135). The greater the reliability coefficient, the more confident one can be that the items in a questionnaire are internally consistent. Therefore, if the omission of a particular item can be shown to increase the overall reliability alpha, than that item should be removed. 
Finally, the consistency of subjects' answers was also taken into consideration before an item was omitted. This was done by analyzing how the response patterns of students on a particular item correlated with their overall score. The assumption would be that advanced subjects would consistently answer easier questions and would only miss the most difficult items. By the same token, it could be assumed that intermediate subjects would not score correctly on the more difficult items and indeed answer more questions incorrectly than the advanced subjects. This is the concept behind inter-item correlation. In other words, if students who have low overall scores pass a question which is missed by students who eventually have large scores, that question is not accurately distinguishing between stronger and weaker students. It would have a low correlation value.

A single number is used to represent how two variables are correlated. A correlation ranges from +1 to -1 . A value of -1 indicates the maximum negative correlation whereas a value of +1 represents the maximum positive correlation (Sprinthall, 1990). In either case, the closer a correlation value is to either +1 or -1 the more strongly it predicts a correlation between two variables. A value of zero represents no correlation. Questions that had low item - total correlations were suspect. The overarching goal of the item analysis was to reasonably ensure that any variance in scores would be due to differences in listening comprehension, rather than the result of poorly written questions.

At the same time, a different goal entered into the decision for keeping or omitting questions. The researcher desired to save a reasonable number of questions for the eventual t-test analysis. Admittedly, had this statistical analysis been conducted prior to final testing, the questionnaire may well have been rewritten, and pretested again before the final battery of questions would have been used for the final test. Be that as it may, an attempt was made to choose 30 questions that would offer some insight as to differences, or the lack thereof, between subjects. In summary, the following four criteria were used in eliminating questions from the questionnaire:

1) Low/negative corrected item-total correlation.

2) Low/negative item-total covariance.

3) Positive change in reliability if item is deleted (Cronbach Alpha).

4) Very high/low item difficulty. 
$\underline{\text { Results of the item - analysis }}$

The test administered in this study was binary. Subjects either passed or failed each test item. In order to judge the difficulty of individual test questions, an additional step was taken to find out the proportion of students who passed an individual test question. This is considered the "item difficulty" value. It is important to note that the item difficulty has an inverse nature to it. For example, an item which has a high difficulty value of .90 was answered correctly by $90 \%$ of the subjects and would, subsequently, be considered an easy question. Similarly, an item with a difficulty value of .30 would be considered low, having been answered correctly by $30 \%$ of the population. Therefore, a high difficulty value represents an easy answer and a low difficulty value represents a difficult question.

Figures 4 and 5 show the percentage of correct answers for each question for the advanced groups combined, the intermediate groups combined, and finally all scores combined. Figures 9-12 in appendix A show how subjects in each group scored on individual test items. The difficulty values reveal that only fifteen questions had difficulty
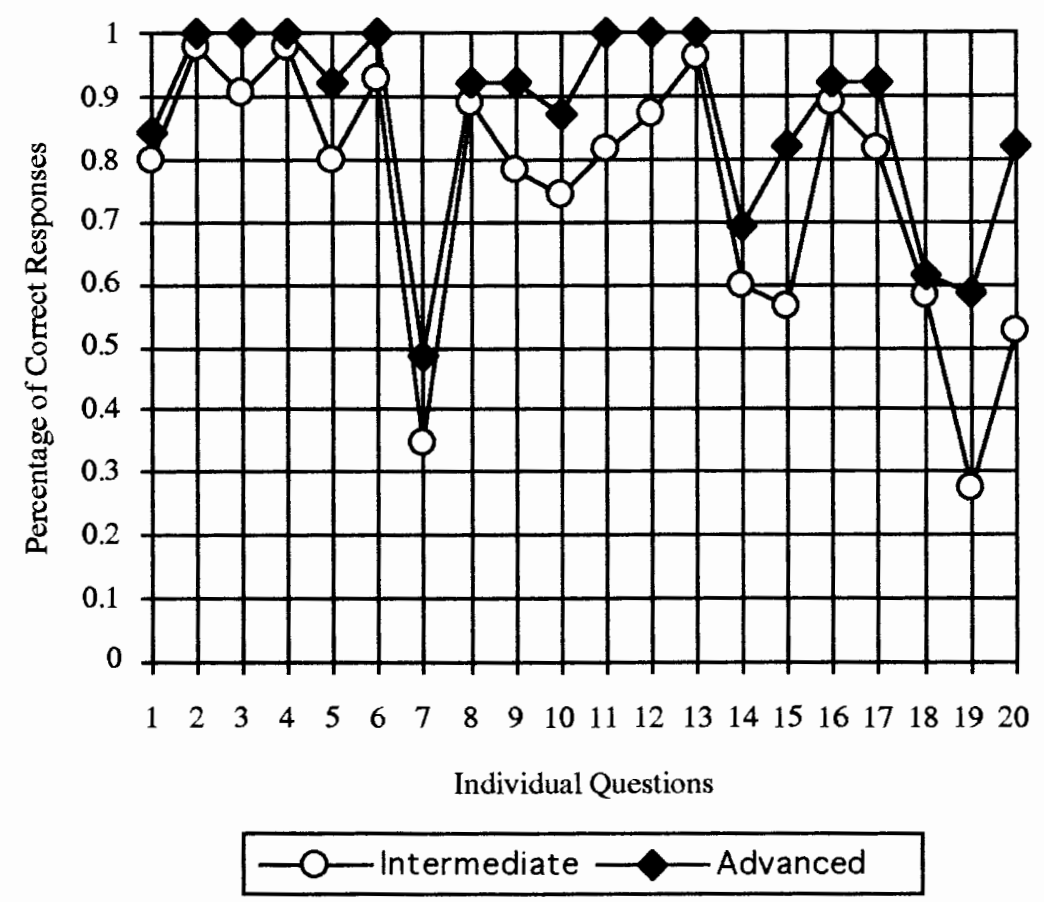

Figure 4. Difficulty values of questions $1-20$ for intermediate, advanced, and all scores combined. 


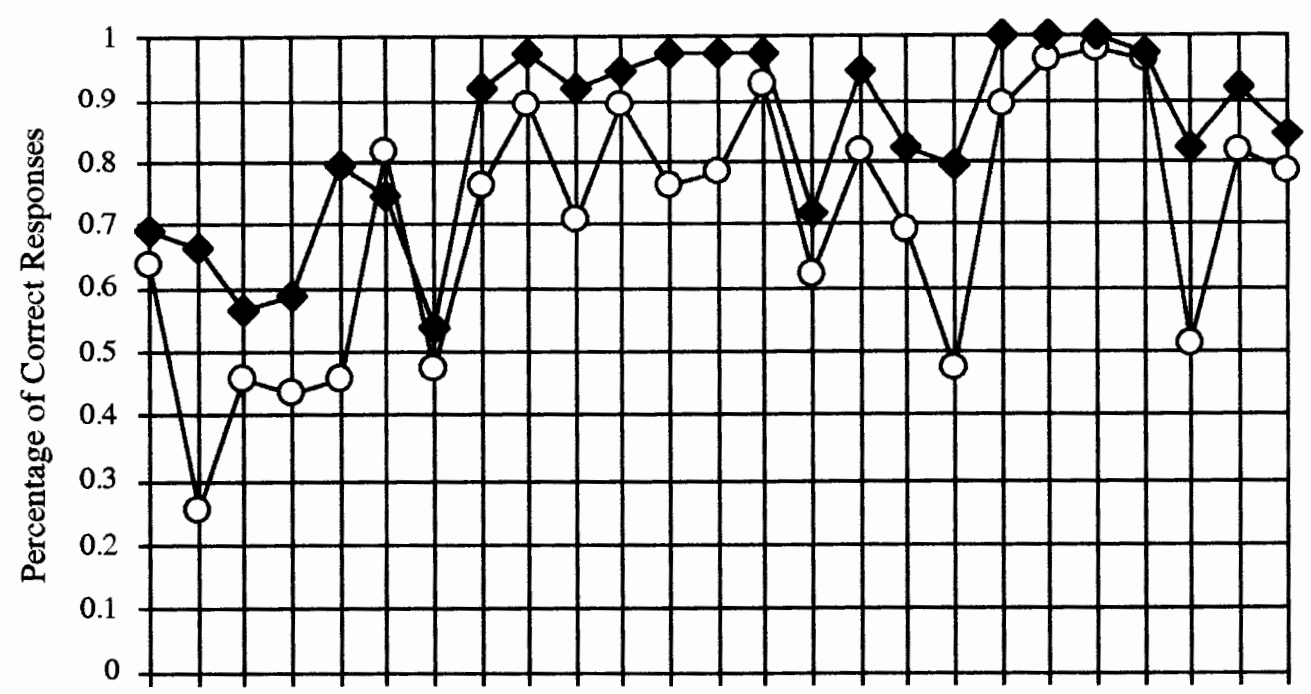

$\begin{array}{lllllllllllllllllllllllll}21 & 22 & 23 & 24 & 25 & 26 & 27 & 28 & 29 & 30 & 31 & 32 & 33 & 34 & 35 & 36 & 37 & 38 & 39 & 40 & 41 & 42 & 43 & 44 & 45\end{array}$

Individual Questions

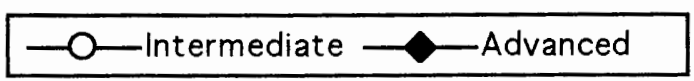

Figure 5. Difficulty values of questions $21-45$ for intermediate, advanced, and all scores combined.

values of less than .7447 . Once again, a difficulty value of 1.00 would indicate that $100 \%$ of the subjects answered the question correctly. The test appears to have been, predictably, easier for the advanced groups, so there is at least a rather clear distinction between proficiency levels. Yet even for the intermediate group, the majority of the difficulty values are above .60 .

In attempting to create a final battery of questions there developed a conflict of goals. On the one hand, if one were attempting to show variance among the advanced groups, certainly the questions with 1.0 difficulty value would be discarded because they reveal no variance whatsoever. For example, the advanced subjects scored perfectly on 10 questions $(2,3,4,6,11,12,13,39,40$, and 41$)$. None of the difficulty values of these questions were 1.0 for the intermediate subjects (although some of them were above .9). If it can be shown that any of these questions reveal a reasonable amount of variance among the intermediate students, then which goal overrides the other? Does one discard a question which only reveals variation in the intermediate group and not the advanced?

One possible solution, which was considered, would be to treat the intermediate and advanced students separately, conduct two separate item analyses, and throw out different questions for each proficiency group. In order to compare cell groups within each 
proficiency level, the same set of questions would have to be shared by both the documentary and lecture group within either the advanced or intermediate groups. This would have resulted in the creation of two different combinations of questions, one for the intermediate subjects and a different set of questions for the advanced group. However, after the two original hypotheses had already been created, it was decided that it would be interesting to compare the results of the lecture and documentary groups between proficiency levels in addition to comparing them within each proficiency level. For example, it would be of some interest to compare the scores of the advanced lecture group with those of the intermediate lecture group. In order to remain consistent, it was necessary to whittle down the 45 - item questionnaire to one final overall battery of questions applying to both the advanced and intermediate groups. Thus all 93 scores were combined and treated as one large group in order to calculate the item-total correlation, item-total covariance, reliability alpha, and the difficulty values.

Figures 6, 7, and 8 are combined graphs showing the corrected item-total correlation and item-total correlation along with the total difficulty value for each individual item. When it came down to finally choosing which questions to omit, it was very much a judgment call on some of the items. Some of the items, for example, 4, 16, 18, 26, 35, and 42 clearly have correlations below .1, though not all of these items had corresponding high difficulty values. Of these same six items, only 4,16 , and 42 have difficulty values over .90 . Items 18,26 , and 35 have difficulty values of $.59, .78$, and .66 respectively. Table VIII in Appendix also shows that the reliability alpha will increase if each of these six items $(4,16,18,26,35$, and 42$)$ were deleted. Given the four criteria used to evaluate given items, in the case of questions 18,26 , and 35 , having a correlation value less than .1 and causing a positive change in the reliability alpha took precedence over the fact that these three items had midrange difficulty values. This is one example of the variables that were considered when choosing which items to omit.

In other cases, there was arguably a small difference between questions which remained and questions that were omitted. For example, item 8 has a difficulty value of .9043 , a correlation value of .1134 , and a covariance value of .2541 . This item was eventually kept in the final battery of items. However, item 41 , which had a difficulty value of .9894 , a correlation value of .1713 and a covariance value of .0987 was omitted. In this case, the combination of a low covariance, low correlation, and high difficulty value caused item 41 to be removed, but slightly lower difficulty value and higher covariance caused item 8 to be kept. 


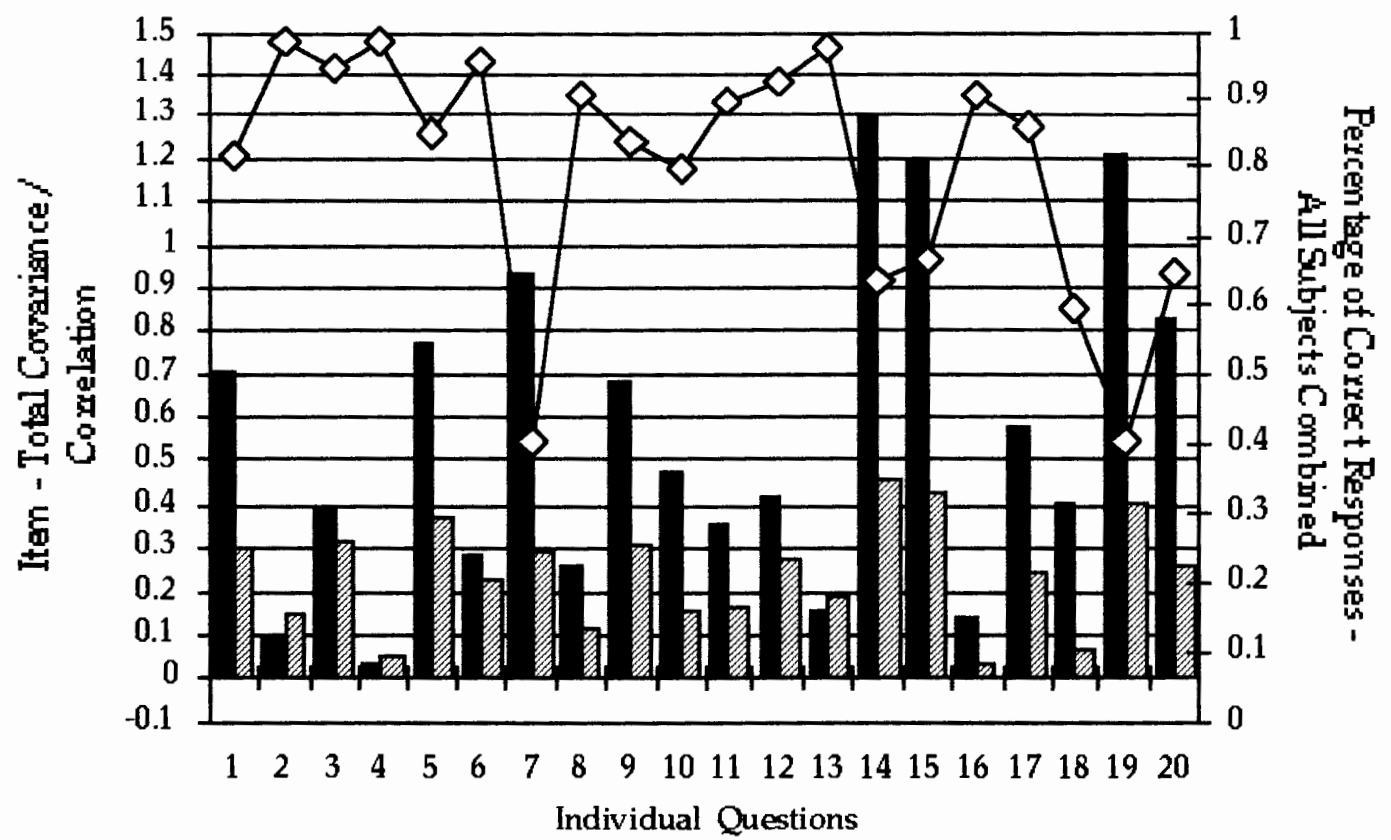

\begin{tabular}{|cc|}
\hline Item-Total Covariance & Corrected Item-Total \\
Correlation & $\checkmark$ Difficulty Values - All \\
Subjects Combined
\end{tabular}

Figure 6. The item - total covariance, item-total correlation, and total difficulty values for questions $1-20$.

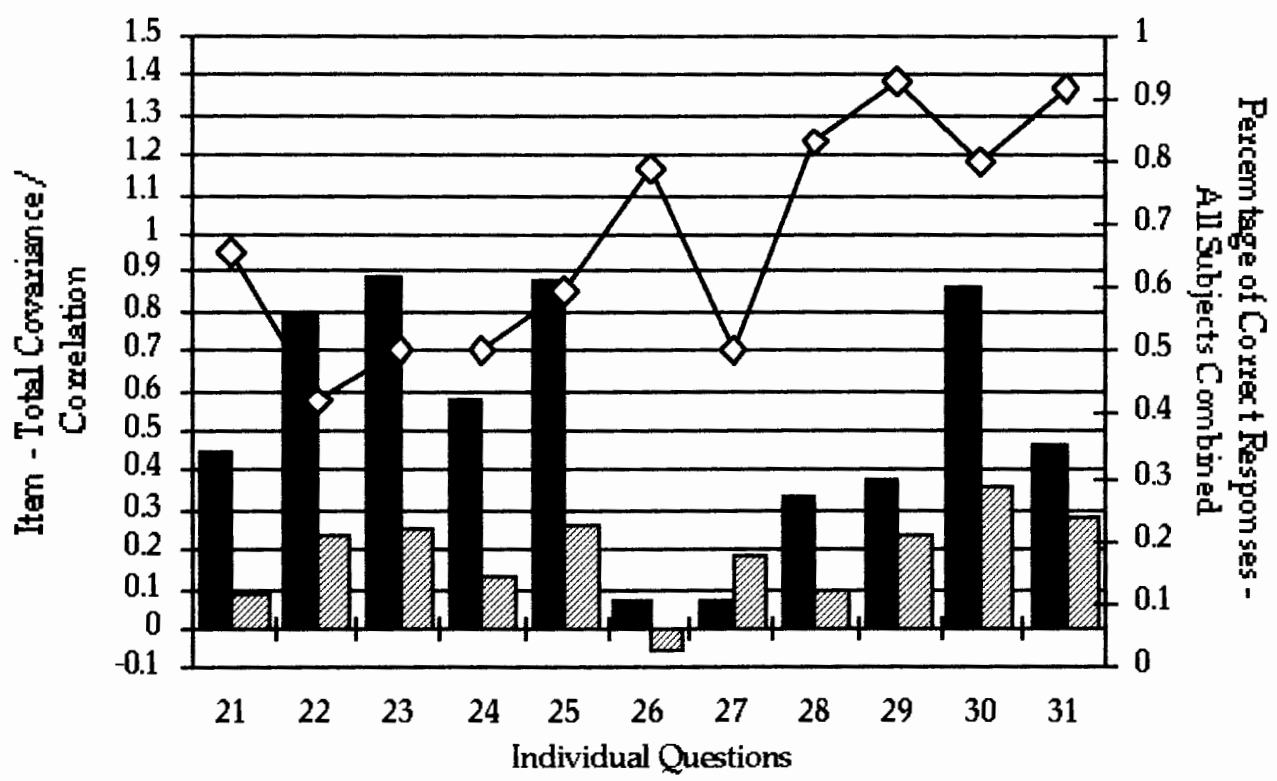

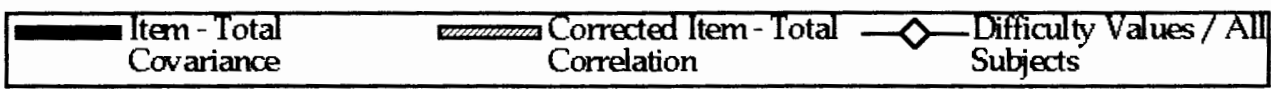

Figure 7. The item - total correlation, item-total covariance, and total difficulty values for questions $21-31$. 


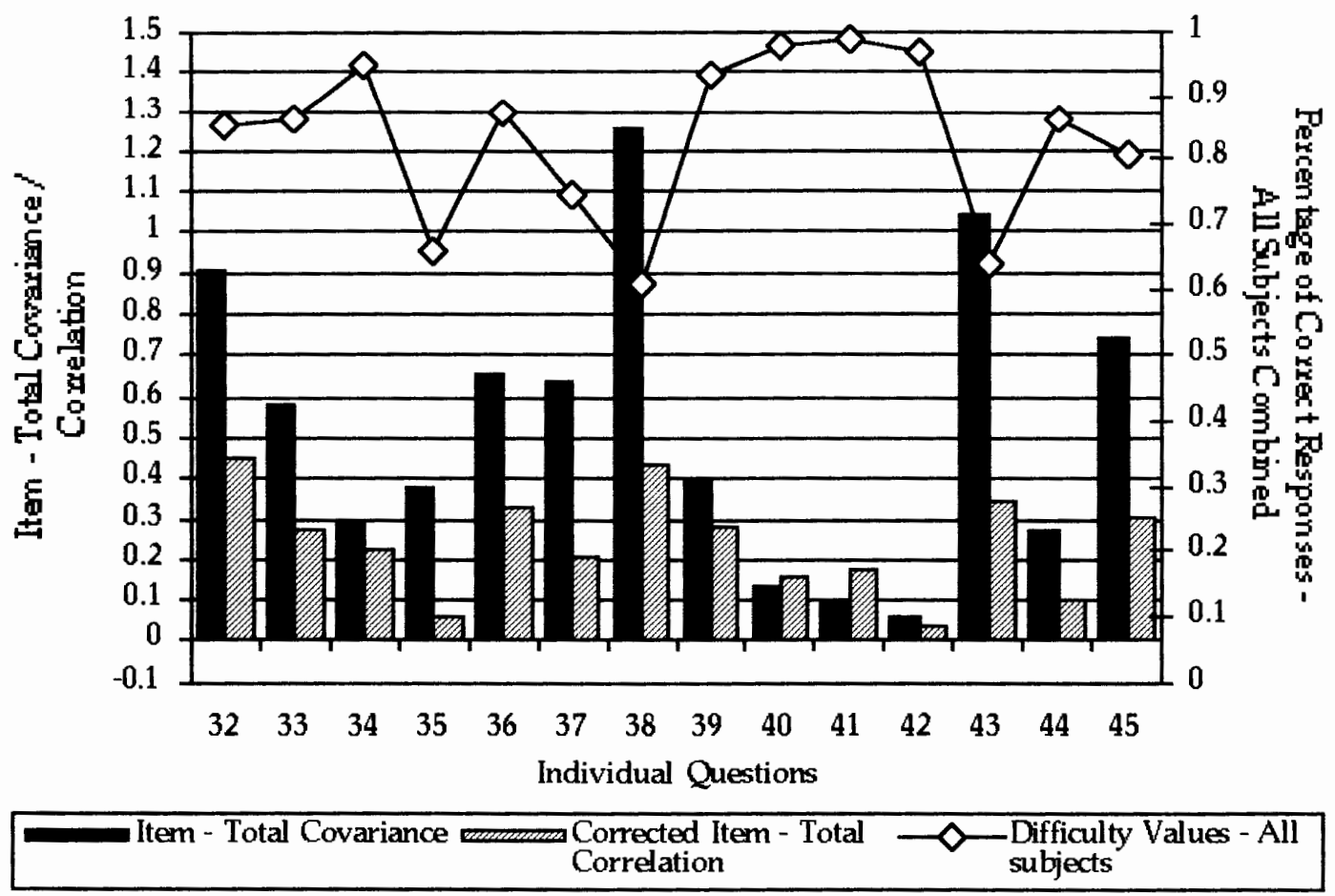

Figure 8. The item - total covariance, corrected item - total correlation, and total difficulty values for questions $32-45$.

In other instances, the combination of a high difficulty and low correlation/covariance value outweighed the fact that a slight drop in reliability occurred when the item was removed. This was the case with items $2,6,13,40$, and 41 , each of which caused the reliability alpha to decrease between .0033 and .0009 . There were, expectedly, a few questions that were on "the borderline" and were ultimately kept for the sake of ensuring a final battery of 30 questions. Item 29 is a case in point. It has a difficulty value of .9255 , a correlation value of .2376 , a covariance value of .3792 , and it caused the reliability alpha to decrease .0041 . Compare item 29 , which was kept, with item 6 , which was omitted. Item 6 has a difficulty value of .9574 , a correlation value of .2342 , a covariance value of .2766 , and it caused the reliability alpha to decrease .0034 . Item 29 has a slightly lower difficulty value and slightly higher covariance and correlation values.

Admittedly, this approach to omitting items was not standardized. It was, however, an attempt to take the four criteria into consideration in order to create a reasonable collection of questions whose scores could be compared in the ANOVA and a 
number of $\mathrm{t}$-tests. The final results of the item-analysis were that the following fifteen items were omitted: $2,4,6,13,16,18,21,24,26,28,35,40,41,42$, and 44 .

As shown in Table 1, once the final 30 questions were determined, the mean score of the test became 22.5319 , the test variance was large at 19.9506 , and the standard deviation was calculated at 4.4666 . The average difficulty value (also called item mean) was .7511, with a minimum score of .4043 and a maximum of .9468 for a range of .5426 . The item variance was .0304 , indicating that most of the scores were clustered around the average difficulty value.

\section{TABLE I}

PRIMARY STATISTICS FOR THE FINAL THIRTY - ITEM QUESTIONNAIRE

\begin{tabular}{llllll}
\hline \multicolumn{2}{c}{ Statisitics for scale: } & Mean & Variance & \multicolumn{2}{c}{ Std. Dev. } \\
Scale $=$ & $\frac{\text { 22.5319 }}{19.9506}$ & \multicolumn{2}{c}{4.4666} & \\
Items $=$ & $\frac{\text { Mean }}{.7511}$ & $\frac{\text { Min. }}{.4043}$ & $\frac{\text { Max. }}{.9468}$ & $\frac{\text { Range }}{.5426}$ & $\frac{\text { Variance }}{.0304}$
\end{tabular}

Standardized item alpha (reliability) $=.7902$

\section{RESULTS OF THE 2 - WAY ANOVA}

When predicting that a significant difference will occur between two testing groups, a probability level, also called the alpha error, is set before the test is conducted. The alpha error indicates how confident one can be in rejecting the null hypothesis. The null hypothesis predicts that any difference which is found between the mean scores of groups will fall within the parameters of what is considered normal. In order to reject the null hypothesis, it must be shown that a difference falls in the extreme right of the distribution, with the mean being the center point of the two extremes. According to Hatch and Lazaraton (1991), in most linguistic research, the null hypothesis will not be rejected unless there is a probability level at or below .05 .

A 2-way analysis of variance (ANOVA) was conducted based upon the mean scores produced from the 30 - item questionnaire. The ANOVA was used because it is able to make multiple comparisons. This study had two independent variables: video treatment and language proficiency. The goal of the ANOVA was to find what effect the video 
variable, proficiency variable, and the combination of the effects of video and profinciency had on variability in the data. As shown in Table II, the ANOVA revealed that proficiency had a significant effect upon the mean scores. The significance of the F-ratio for profinciency level was $.000(\mathrm{~F}<.05)$. However, the significance of the F-ratio for the video variable was $.424(F>.05)$. The significance of $F$ for the combination of the video and profinciency variables was .349 (also $>.05$ ). Therefore, there was not a significant interaction effect caused by the documentary video and the hypothesis was not supported.

\section{TABLE II}

RESULTS OF 2 - WAY ANOVA

\begin{tabular}{|c|c|c|c|c|c|}
\hline Source of Variation & $\begin{array}{l}\text { Sum of } \\
\text { Squares }\end{array}$ & $\underline{\mathrm{df}}$ & $\begin{array}{c}\text { Mean } \\
\text { Squares }\end{array}$ & $\underline{F}$ & $\begin{array}{l}\text { Sig } \\
\text { of } F\end{array}$ \\
\hline \multicolumn{6}{|l|}{ Main Effects } \\
\hline Level & 518.532 & 1 & 518.532 & 36.267 & .000 \\
\hline Tape & 9.213 & 1 & 9.213 & .644 & .424 \\
\hline \multicolumn{6}{|l|}{ 2-Way Interactions } \\
\hline Level/Tape & 12.697 & 1 & 12.697 & .888 & .349 \\
\hline Residual (error) & 1286.779 & 90 & 14.298 & & \\
\hline
\end{tabular}

\section{RESULTS OF T-TESTS}

Having completed the item analysis and the ANOVA, a series of $t$-tests were also conducted in order to isolate a number of different combinations of cell groups. A Case $2 \mathrm{t}$-test (Hatch \& Lazaraton, 1991) is one in which the mean scores of two independent groups are compared. When one of the two groups is predicted to obtain higher mean scores, the alpha error must be set at .01. When no difference is predicted, an alpha error of .05 can be met in order to reject the null hypothesis.

Five Case $2 \mathrm{t}$-tests were conducted based on the four groups scores on the modified 30-question test. A Case $2 \mathrm{t}$-test is a statistical measurement used to measure if a significant difference exists between two means - a difference which is not a product of chance. If a number of pairs of test groups are compared, a frequency distribution of all the means of all of the groups could eventually be calculated. A standard "group" deviation could be calculated. The standard deviation of this distribution would be called the "estimate of the standard error of difference" (SE of D) (Hatch \& Lazaraton, 1991: 259). 
The result of the $t$-test is a"t-value" which equals the difference between the sample means divided by the SE of D (or standard "group" deviation).

Firstly, to test the hypothesis, the mean scores of the intermediate lecture and intermediate documentary groups were compared. As shown in Table III, the measurement of the two-tailed significance is .256 . Since a the hypothesis specifically predicts which of the two groups will have the greater mean score, in this case the documentary group, this ttest is considered a one-tailed $t$-test. The calculations of a two-tailed and a one-tailed $t$-test are identical. The only difference is determining which probability error to use and the diffence that must exist between the means of two groups for that probability error to be met. The probability error of a two-tailed $t$-test, at .05 , is a less conservative probality error than that of a one-tailed t-test, which is at .01 . Therefore, if the probability level is not met at the .05 level, it is certainly not going to be met at the .01 alpha error of a onetailed t-test. Therefore, because the two-tailed significance was found to be $.256(\mathrm{P}>.05)$, the difference between the means cannot be considered significant and the null hypothesis should not be rejected.

By the same token, when the means of the advanced lecture and advanced documentary groups were compared, as seen in Table IV, the measurement of two-tailed significance was .893 ( $\mathrm{P}>.05$ ), well above the .05 alpha error necessary to reject the null hypothesis. Therefore, there also was not a significant difference in the mean scores between the advanced groups.

Although not initially a part of a hypothesis for the study, two additional t-tests were also conducted. One $t$-test compared the mean of the advanced lecture group with that of the intermediate lecture group. The second t-test compared the mean of the advanced documentary group with that of the intermediate documentary group. Thus, $t$-tests were conducted both within and across proficiency levels.

When the intermediate and advanced lecture groups were compared, as shown in Table V, a significant difference between the means did occur. Once again, the alpha error of the two-tailed test was set at .05 . The measurement of significance was .000 $(\mathrm{P}<.05)$. Therefore, there is a $100 \%$ chance of being correct in rejecting the null hypothesis. 
TABLE III

CASE 2 T-TEST COMPARING THE MEAN SCORES

OF THE INTERMEDIATE - LECTURE AND

INTERMEDIATE - DOCUMENTARY GROUPS

\begin{tabular}{|c|c|c|c|c|}
\hline \multicolumn{5}{|c|}{ REVISED TOTAL 1 (30 ITEMS) } \\
\hline Variable & $\begin{array}{l}\text { Number } \\
\text { of Cases }\end{array}$ & Mean & $\begin{array}{l}\text { Stand. } \\
\text { Dev. }\end{array}$ & $\begin{array}{l}\text { Standard } \\
\text { Error of Mean }\end{array}$ \\
\hline $\begin{array}{l}\text { Int. Lecture } \\
\text { Int. Doc. }\end{array}$ & $\begin{array}{l}24 \\
31\end{array}$ & $\begin{array}{l}21.2917 \\
19.9032\end{array}$ & $\begin{array}{l}4.165 \\
4.650\end{array}$ & $\begin{array}{l}.850 \\
.835\end{array}$ \\
\hline \multicolumn{5}{|c|}{ Mean Difference $=1.3884$} \\
\hline \multicolumn{5}{|c|}{ t-test for Equality of Means } \\
\hline t-value & 2-Tail Sig & \multicolumn{2}{|c|}{ SE of Diff } & \\
\hline 1.12 & .256 & \multicolumn{2}{|c|}{1.209} & \\
\hline
\end{tabular}

TABLEIV

CASE 2 T-TEST COMPARING THE MEAN SCORES

OF THE ADVANCED LECTURE AND ADVANCED DOCUMENTARY GROUPS

\begin{tabular}{|c|c|c|c|c|c|}
\hline \multicolumn{6}{|c|}{ REVISED TOTAL 1 (30 ITEMS) } \\
\hline Variable & & $\begin{array}{l}\text { Number } \\
\text { of Cases }\end{array}$ & Mean & $\begin{array}{l}\text { Stand. } \\
\text { Dev. }\end{array}$ & $\begin{array}{l}\text { Standard } \\
\text { Error of Mean }\end{array}$ \\
\hline Adv. Lect. & & 21 & 25.3333 & 2.763 & .603 \\
\hline Adv. Doc. & & 18 & 25.4444 & 2.255 & .532 \\
\hline \multicolumn{6}{|c|}{ Mean Difference = -.1111 } \\
\hline \multicolumn{6}{|c|}{ t-test for Equality of Means } \\
\hline t-value & $\mathrm{df}$ & 2-Tail Sig & \multicolumn{2}{|c|}{ SE of Diff } & \\
\hline-.14 & 37 & .893 & \multicolumn{2}{|c|}{.817} & \\
\hline
\end{tabular}




\section{TABLE V}

CASE 2 T-TEST COMPARING THE MEAN

SCORES OF THE INTERMEDIATE

AND ADVANCED LECTURE GROUPS

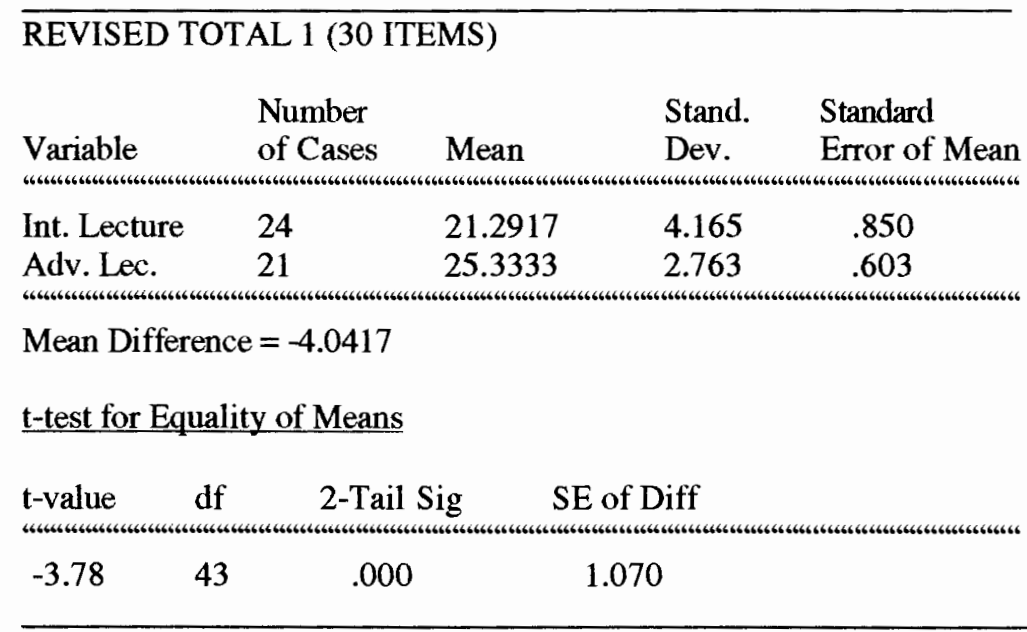

A significant difference also was calculated between the means of the intermediate and advanced documentary groups, as seen in Table VI. The measurement for two-tailed signficance was also calculated at $.000(\mathrm{P}<.05)$. Again, one can be certain that the null hypothesis should be rejected, indicating that a significant difference occured between the two groups.

For the sake of curiosity, one additional $t$-test was conducted to see if any significant differences existed when the combined scores of the advanced and intermediate documentary subjects were compared with those of all of the lecture subjects combined. This final t-test is shown in Table VII (shown on page 45) and indicates that there was no significant difference when such a combination of students was calculated because the measurement of significance is $.181(\mathrm{P}>.05)$. This was likely influenced by the fact that the mean scores of the advanced groups were virtually identical. 
TABLE VI

CASE 2 T-TEST COMPARING THE MEAN SCORES OF THE ADVANCED AND INTERMEDIATE DOCUMENTARY GROUPS.

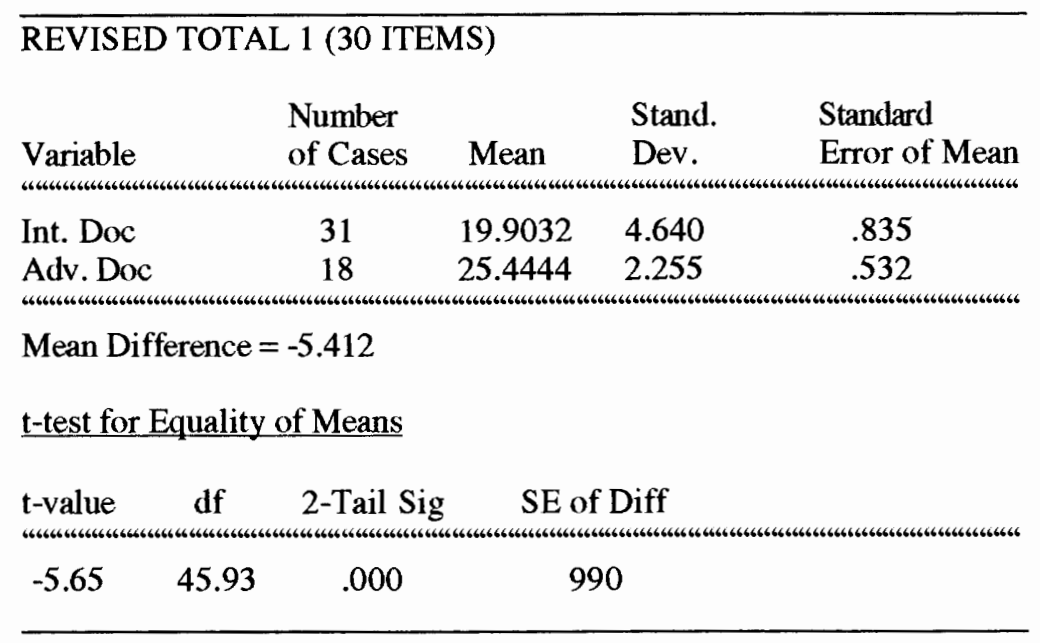

TABLE VII

CASE 2 T-TEST COMPARING THE MEAN SCORES

OF ALL LECTURE SUBJECTS COMBINED WITH THOSE OF ALL DOCUMENTARY SUBJECTS COMBINED

REVISED TOTAL 1 (30 ITEMS)

\begin{tabular}{|c|c|c|c|c|}
\hline Variable & $\begin{array}{l}\text { Number } \\
\text { of Cases }\end{array}$ & $\begin{array}{l}\text { Stand. } \\
\text { Mean }\end{array}$ & $\begin{array}{l}\text { Standard } \\
\text { Dev. }\end{array}$ & Error of Mean \\
\hline Total Lec. & 45 & 23.1778 & 4.086 & .609 \\
\hline Total Doc. & 49 & 21.9388 & 4.754 & .679 \\
\hline
\end{tabular}

Mean Difference $=1.2390$

t-test for Equality of Means

\begin{tabular}{cccc} 
t-value & df & 2-Tail Sig & SE of Diff \\
1.35 & 92 & .181 & .918 \\
\hline
\end{tabular}




\section{CHAPTER V}

\section{DISCUSSION}

The results of the ANOVA and the series of $t$-tests revealed no significant difference in test scores between the lecture and documentary groups at either level. It was presumed that the visuals in the documentary video would provide a richer visual schema and enable the intermediate students viewing it to comprehend more of the aural input than the intermediate subjects who only viewed a single speaker. The test results suggest that at both levels, the different visuals of the videos did not positively or negatively affect the subjects' ability to answer the true/false questionnaire. This could be due to a number of factors: the subjects, the test itself, the nature of the testing procedure, and/or a possibility that the documentary visuals simply do not affect listening comprehension any better than the lecture visuals.

It is also possible that the intermediate students, similar to the advanced students, had proficient language skills to process the aural information effectively and make the visuals superfluous. Perhaps the addition of a group with even lower language proficiency would have revealed a difference between the two tapes. It also would have been interesting to include a control group of native English speakers. The results of this group could have been compared with those of the ESL groups to gain insight as to the effectiveness of video images for native speakers.

Another question that remains is whether or not the nature of the questionnaire or testing method somehow neutralized any potential difference that the documentary visuals would have provided. In order to prevent the test from becoming a test of short term memory, rather than of listening comprehension, the researcher wanted subjects to be able to demonstrate their comprehension as quickly as possible after hearing a fact stated in the narrative. Allowing the subjects to have the questions in front of them while they watched seemed the most feasible way to let the students accomplish this. Asking the questions orally would have required that the video be paused while either the researcher asked the questions or the students listened to recorded questions. Either way, the input would have needed to be stopped and the subjects would have had to depend upon their short term memories even more in order to answer the questions. 
A different option for testing the subjects could have been to superimpose questions on the video screen or project them on a separate screen, such as with an overhead projector, rather than print them on sheets of paper. This would have enabled the researcher to fully control the timing and the pace at which students would have been allowed to read the questions. The first option was not technically feasible and the latter option would have faced the risk of students being unable to read the projected questions effectively. Therefore, it was decided to have the subjects answer printed questions while the video tapes played, although this created a problem and a regrettable compromise. Reading the questions interfered with the subjects' ability to maintain eye contact with the television screen.

The researcher took field notes while the subjects answered the questionnaire during the second showing of the videos and all but three of the subjects who watched the lecture video, both intermediate and advanced, kept their eyes down and focused on their questionnaires as they answered the questions. They did not raise their eyes once while the tape was running. Therefore, the desire to allow subjects to answer immediately after the moment of input was compromised by the fact that the printed questions competed for the visual attention of the subjects. Certainly the subjects could not simultaneously watch the television and look at their questionnaires. The vast majority of the lecture subjects chose to focus their attention on their questionnaires during the second showing of their respective video and only raised their eyes after the tape had been paused and the researcher began to address them. This problem was also prevalent in the documentary groups, but approximately fifteen percent of these subjects did look up at the screen at least once during the course of the second showing.

The intent of this study was to compare the different visuals on the television screen. Yet this desire was compromised by the third set of visual information, namely, the printed questions on the page. If their heads were down, the documentary and lecture subjects basically took the same listening test. Seeing the tape one time through, before answering any questions, apparently wasn't enough to set the groups apart. Without abandoning schema theory as a pertinent theory in which to ground a video pedagogy for second language learning, the lack of visual contact with the screen may be the most viable explanation as to the similarity in scores between the groups.

In addition to pulling the visual attention of the subjects away from the television screens, the printed questions themselves also may have instantiated schema in the minds of the students, effectively preparing them to anticipate particular information in the 
narration. This, therefore, may also have made them less dependent upon the aid of the visuals. By reading the questions aloud, before the second showing of the video, the students knew what information to listen for. If the intermediate documentary group was to have an advantage over the intermediate lecture group, it may have been neutralized by the lecture group's ability to read and hear the questions read before actual testing.

Given that there were no control groups of subjects who were only permitted to answer questions after watching the videos, as opposed to during the videos' showing, it is unclear to what extent answering questions during the video inhibited the visuals from instantiating schema within the subjects. The researcher assumes that if virtually all of the intermediate students focused their attention away from the television screen, essentially, their treatments were identical. They reduced the video listening exercise to strictly an audio listening exercise. Although a larger percentage of advanced students did glance up at the screen periodically while answering the questions, it was still a minority of the students. Therefore, the students who did not look at the screen essentially neutralized the differences that may have been brought about by the visuals on the screen.

Lastly, it may also be true that there simply is no significant difference between the way that seeing a speaker talk and seeing accompanying documentary images affect listening comprehension. If a scale were to be created with the most relevant images at the top and the least relevant at the bottom, it is possible that the image of a speaker and the documentary footage in the second tape may both be at similar places on that scale.

\section{LIMITATIONS}

The primary limitations of this study concern the subject group, the nature of the questionnaire, and the testing method. Permission to access the subjects for this study was provided by the faculty of the three language programs. The researcher was dependent upon the assumption that the subjects were accurately placed in their respective groups. With the exception of the subjects from the independent group, it was not feasible to independently verify the placement scores of the subjects. Added to this, this study made no objective attempt, such as with a pretest, to evaluate any prior knowledge of Costa Rica that subjects may have had. This decision was made because of restricted testing time. The researcher did indeed omit two questionnaires completed by subjects who were from Latin American countries and who informally spoke with the researcher following testing. However, even this was a subjective choice on the part of the researcher. A pretest would 
have been a more thorough approach to judging whether or not subjects had any prior knowledge of Costa Rica which may have biased their answers. Another limitation concerning the subjects was that by dividing ninety-four subjects into four cell groups, it can be argued that neither cell group had a significant number of subjects within it. The largest cell group had thirty-one subjects and the smallest contained eighteen.

In addition to the limitations involving the creation of the subject pool, the nature of the questionnaire itself limits the conclusions that can be derived from the results. Firstly, the questionnaire was a strict binary test. A subject who guessed at any given question would have a far greater chance of getting the question correct than if the question gave a number of choices or required a short written answer. This is not to say that a true/false questionnaire is not valid, but rather that it is limited in its accuracy to show the extent of comprehension. The final battery of questions that was used was small, totaling thirty questions. Indeed it could not fully test the information that the students may have comprehended. More could have been understood than was required to answer the questions. In this sense, the true/false questionnaire cannot be a complete enough measurement of the differences that may have existed between the intermediate documentary group's comprehension and that of the intermediate group. Certainly a true/false questionnaire is only one small part of a variety of testing measurements needed to reveal any differences in comprehension due to a change in visuals.

Possibly the most significant limitation of the study concerns the issue of allowing the subjects to answer the questions as they viewed the tapes. As discussed in the previous section, this caused a conflict between the two primary types of visual information: the printed words on the questionnaire and the motion pictures on the television screen. This effectively prevented the visuals in the respective videos from being adequately isolated.

\section{FUTURE RESEARCH}

It is apparent that a number of variables make this study's validation of the schema theory inconclusive. To reveal the effect that video images play on second language listening comprehension, a number of issues must be addressed. Firstly, assuming that the videos used in this study were appropriate sources of audio/visual input, alternative testing measurements must be attempted before the current theory can be supported or rejected. The primary challenge of testing the impact that different visuals have on listening comprehension lies in effectively isolating the visuals as the only source of contextual 
information aside from the audio input. The tension will be between keeping subjects' attention solely on the visuals in the video while at the same time testing those same subjects as soon as possible after the moment of input, thus keeping the test more one of comprehension than one of memory. This study demonstrated that when given the choice of either glancing back and forth between the test page and the television or focusing solely on the test questionnaire, most students will focus on the printed questions alone.

One direction that the study points is toward the use of interactive video and computer assisted learning. These two technologies may be the ones most likely to allow questions to be superimposed on the same screen on which visuals appear. For example, if either of the videos in this study were to appear in a format where a subject could answer questions on a computer monitor or a television, using a keyboard or joystick, than that subject's visual attention could be maintained with the screen. There could either be a pause in the video, after which the questions of a given section would then appear, or the questions could appear on a part of the screen while the video, on a separate part of the screen, continued to run. In this latter case, the subjects could at least use their peripheral vision to maintain visual contact with the video. With the increasing availability of interactive computer programs, the technology needed to test this theory is likely available.

Another implication of the current study is that testing simultaneously or close to the moment of input may actually not reveal the difference between the documentary and lecture visuals. Research is needed to test how quickly short term memory erodes after the moment of input. It could be that, similar to the Bransford and Johnson (1973) study, visuals play a great role in long term memory. In that study the subjects were tested after they had heard the entire ambiguous paragraph read to them. A similar method could be undertaken with the two videos used in this study. If the subjects simply watched the videos twice and then took the questionnaire, would a significant difference emerge? Perhaps students could be tested at various time intervals following the showing of the respective tapes. Some students could answer questions as the tape runs, others could answer questions at the end of each section, while a third group could answer the tests only after watching the video in its entirety. Testing at different time intervals may reveal a significant difference between the two videos.

Qualitative research will also be necessary to reveal any difference in the amount and nature of content that is comprehended. A researcher could sit next to and interview a subject throughout the viewing, noting the information that the subject reports. Researchers could lead subjects through a guided recall, asking specific questions and 
having subjects write out their responses. Subjects could also be asked to write an outline of the narration, including as many details as they can, after watching either a section of the video or the entire video. In addition, any of these future studies would benefit from the inclusion of control groups of native English speakers. The Schema theory has implications upon learning in both a first and second language. It would be interesting to see results found among ESL students also were found among native English speakers.

In summary, if the video input remains the same, then a number of testing methods can be attempted to flush out any differences upon listening comprehension. If subjects are to be tested at the same time as they receive the audio/visual input, then the test must not interfere with the subjects' ability to either see the visuals or to hear the audio track. If the subjects are to read the questions, they will need to appear on the same screen as the visuals. If the subjects are to hear the questions, then the questions must not interfere with their processing of the audio input from the tape.

Secondly, other types of measurements, such as multiple choice tests, short answer, full or partial recall, and interviewing techniques should also be attempted. Testing should be done at different intervals following the playing of the tapes. All these testing methods could be done with the same two tapes used in this study. An additional direction that research must go is in the further creation of a taxonomy of relevant visual images. A variety of visual input must also be tested. How much audio input would be comprehended if a subject heard a description of a house fire while watching video images of ducks swimming in a pond? Are visuals the powerful "shapers" of context that the discussed literature suggests that they are? Will the subjects recall something like "ducks were caught in a house fire", or will information from one of the channels dominate in short and/or long term memory? Certainly it is unlikely that ESL instructors would use a videotape whose visuals are totally unrelated to the soundtrack. However, it is still necessary to start at that extreme and work back in to see if any taxonomy of relevant visuals appears. If research can flush out even some general guidelines as to ways to evaluate video productions, there will be less guesswork and happenstance in the choice of video material for developing second language listening skills. 


\section{REFERENCES}

Adams, J. A. (1982). Scripts and the recognition of unfamiliar vocabular: enhancing second language skills. Modern Language Journal, 66, 155-159.

Altman, R. (1990). Toward a new video pedagogy: the role of schema theory and discourse analysis. IALL Journal of Language Learning Technologies, 23(1), 9-16.

Anderson, J.R. (1980). Cognitive psychology and its implications. San Francisco: W.H. Freeman and Company.

Amold, D. J., \& Brooks, P. H. (1976). Influence of contextual organizing material on children's listening comprehension. Journal of Educational Psychology, 68(6), 711-716.

Asher, J. J. (1969). The total physical response approach to second language learning. Modern Language Journal, 53(1), 3-17.

Ausubel, D. P. (1963). The psychology of meaningful verbal learning. New York: Grune \& Stratton.

Ausubel, D. P. (1968). Educational psychology: a cognitive view. New York: Holt, Rinehart \& Winston, Inc.

Baggett, D., \& Ehrenfencht, A. (1983). Encoding and retaining information in the visuals and verbals of an educational movie. Educational Communication and Technology Journal, 31, 23-32.

Barlett, F. C. (1932). Remembering. Cambridge, England: Cambridge University Press.

Barrow, L. C., \& Westley, B. H. (1959, Winter). Comparative teaching effectiveness of radio and television. AV Communication Review, Z(1), 14-23.

Beagles-Roos, J., \& Gat, I. (1983). Specific impact of radio and television on children's story comprehension. Journal of Educational Psychology, 75 (1), 128-137.

Bower, G. H., Black, J. B., \& Turner, T. J. (1979). Scripts in memory for text. Cognitive Psychology, 11, 177-220.

Bransford, J. D., \& Johnson, M. K. (1973). Considerations of some problems of comprehension. In William G. Chase (Ed.), Visual information processing (pp. 383-438). New York: Academic Press. 
Bransford, J. D., \& Johnson, M. K. (1977). Contextual prerequisites for understanding: some investigations of comprehension and recall. Journal of Verbal Learning and Verbal Behavior, 11, 717-726.

Brown, G. B. (1987). Twenty-five years of teaching listening comprehension. English Teaching Forum, 25, 11-15.

Brown, H. D. (1987). Principles of Language Learning and Teaching. Englewood: Prentice Hall Regents.

Byrnes, H. (1984). The role of listening comprehension: A theoretical base. Foreign Language Annals, 17(4), 317-329.

Call, M. E. (1985). Auditory short-term memory, listening comprehension, and the input hypothesis. TESOL Quarterly, 19(4), 765-781.

Carrel, P. L. \& Eisterhold, J. C. (1983). Schema theory and ESL reading pedagogy. TESOL Quarterly, 17(4), 553-573.

Chastain, K. D. (1979). Testing listening comprehension tests. TESOL Quarterly, $\underline{13}(1), 81-88$.

Chomsky, N. (1959). A review of B.F. Skinner's verbal behavior. Language, 35, 26-58.

Clark, H. H., \& Clark, E. V. (1977). Psychology and language. New York: Harcourt Brace Jonanovich.

Drew, D. G., \& Reese, S. D. (1980). Children's learning from a television newscast. Journalism Quarterly, 61, 83-88.

Dunkel, P. (1986). Developing listening fluency in L2: theoretical principles and pedagogical considerations. The Modern Language Journal, 70(2), 99 - 105.

Greenfield, P. M. \& Beagles-Roos, J. (1988). Television vs. radio: the cognitive impact on different socioeconomic and ethnic groups. Journal of Communication, $\underline{38}(2), 71-92$.

Gunter, B., Furnham, A., \& Gietson, G. (1984). Memory for the news as a function of the channel of communication. Human Leaming, $3,265-271$.

Ferguson, G. A. (1981). Statistical analysis in psychology and education. New York: McGraw-Hill, 419-431.

Hartman, F. R. (1961). Single and multiple channel communication: a review of research and a proposed model. AV Communication Review, 9, 235-262.

Hatch, E., \& Lazarton, A. (1991). The research manual: Design and statistics for applied linguistics. New York: Newbury House Publishers. 
Hayes, D. S., Kelly, S. B., \& Mandel, M. (1986). Media differences in children's story synopses: radio and t.v. contrasted. Journal of Educational Psychology, 78(5), 341-346.

Hsia, H. J. (1968). On channel effectiveness. AV Communication Review, 16(3), 245-267.

Hsia, H. J. (1971). The information processing capacity of modaling and channel performance. AV Communication Review, 19(1), 51-75.

Kitao, S. K. (1989). Reading, schema theory and second language learners. Tokyo: Eichosa Shinsa Co. (ERIC Document Reproduction Service. ED 314 937)

Krashen, S. D. (1987). Applications of psycholinguistic research to the classroom. In M. H. Long and J. C. Richards (Eds.), Methodology in TESOL (pp. 33-44). New York: Newbury House Publishers.

Lonergan, J. (1984). Video in language teaching. Cambridge, Mass.: Cambridge University Press.

Long, D. R. (1989). Second language listening comprehension: a schematheoretic perspective. The Modern Language Journal, 73, 32-40.

MacWilliam, I. (1986). Video and language comprehension. ELT Journal, 40, 131-35.

Mandler, J. M. (1984). Stories, scripts, and scenes: Aspects of schema theory. Hillsdale, New Jersey: Lawrence Erlbaum Associates.

Mayer, R. E. (1975). Information processing variables in leaming to solve problems. Review of Educational Research, 45(4), 525-541.

Mueller, G. A. (1980). Visual contextual cues and listening comprehension: an experiment. The Modern Language Joumal, 64(3), 335-340.

Nasser, D. L., \& McEwen, W. J. (1976). The impact of alternative media channels: recall and involvement with messages. AV Communication Review, 24(3), 263-272.

Neisser, U. (1976). Cognition and reality. San Francisco: W. H. Freeman \& Company.

Nord, J. R. (1981). Three steps leading to listening fluency: A beginning. In $\mathrm{H}$. Winitz (Ed.), The comprehension approach to foreign language instruction (pp. 69-100). Rowley, Mass.: Newbury House Publishers.

Ortmeyer, C. R., \& Goldstein, B.L. (1980). Comparing modes of instruction used in learning to listen and understand English as a second language.

(ERIC Document Reproduction Service. ED 202 240)

Parry, T.S., \& Meredith, R. A. (1984). Videotape vs. audiotape for listening comprehension tests: an experiment. OMLTA Journal, 47-53.

(ERIC Document Reproduction Service. ED 254 107). 
Pavio, A. (1975). Perceptual comparisons through the mind's eye. Memory and Cognition, 3 , 635-647.

Popham, J. W. (1990). Modern educational measurement: a practitioner's perspective. Englewood Cliffs, New Jersey: Prentice Hall, 121 - 137.

Postovsky, V. A. (1981). The priority of aural comprehension in the language acquisition process. In $\mathrm{H}$. Winitz (Ed.), The comprehension approach to foreign language instruction (pp. 170-186). Rowley, Mass.: Newbury House Publishers

Pritchard, R. (1988). The effects of cultural schemata on reading processing strategies. (Report No. CS 009273). Fresno, CA: California State University. (ERIC Document Reproduction Service. ED 298 430)

Pryluck, C., Teddlie, C., \& Sands, R. (1982). Meaning in film/video: order, time and ambiquity. Journal of Broadcasting, 26(3), 685-696.

Reese, S. D. (1984). Visual-verbal redundancy effects of television news learning. Journal of Broadcasting, 28(1), 79-87.

Richards, J. C. (1983). Listening comprehension: approach, design, procedure. TESOL Quarterly, 17(2), 219-239.

Rivers, W. M. (1971). Linguistic and psychological factors in speech perception and their implications for teaching materials. In P. Pimsleur \& T. Quinn (Eds.), The psychology of second language learning (pp. 123-134). Cambridge, Mass.: Cambridge University Press

Rumelhart, D. E. (1980). Schemata: the building blocks of cognition. In R. J. Spiro, B. C. Bruce, \& W. F. Brewer. (Ed.). Theoretical issues in reading comprehension (pp. 33-58). Hillsdale, New Jersey: Lawrence Erlbaum Associates.

Rumelhart, D. E. (1984). Understanding understanding. In J. Flood (Ed.), Understanding reading comprehension: cognition, language and the structure of prose. Newark, Deleware: International Reading Association.

Salomon, G. (1974). What is learned and how it is taught: The interaction beween media, message, task, and learner. In D. R. Olson (Ed.), Media and symbols: the forms of expression, communication, and education (pp. 383-406) Chicago: The National Society for the Study of Education.

Schallert, D. L. (1982). The significance of knowledge: a sythesis of research related to schema theory. In W. Otto \& S. White (Eds.), Reading expository material (pp. 13-41). New York: Academic Press.

Schank, R. C., \& Abelson, R. P. (1977). Scripts, plans, and knowledge. In P.N. Jounson-Laird \& P. C. Wason (Eds.), Thinking: Readings in cognitive science (pp. 421-432). Cambridge: Cambridge University Press. p. 421-432.

Severin, W. (1967a). The effect of relevant pictures in multiple-channel communications. AV Communication Review, 15(4), 386-401. 
Severin, W. (1967b). Another look at cue summation. AV Communication Review, 15(3), 233-245.

Sprinthall, R. C. (1990). Basic statistical analysis (third edition). Englewood Cliffs, New Jersey: Prentice Hall.

Spiro, R. J. (1980). Constructive processes in prose comprehension and recall. In R. J. Spiro, B. C. Bruce, \& W. F. Brewer. (Eds.), Theoretical issues in reading comprehension (pp. 245-278). Hillsdale, New Jersey: Lawrence Erlbaum Associates

Travers, R. M. W. (1964). The transmission of information to human receivers. AV Communication Review, 12, 373-385.

Tyson, M. (1989). The effect of media on the listening comprehension scores of intermediate ESL students. Unpublished M.A. Thesis, Portland State University, Portland, OR.

Young, D. J. (1989). Activating student background knowledge in a take charge approach to foreign language reading. Arlington, Virginia:

(ERIC Document Reproduction Service. ED 314 931) 
APPENDIX A

RESPONSE PATTERNS 


\begin{tabular}{|c|c|c|c|c|c|c|c|c|c|c|c|c|c|c|c|c|c|c|c|}
\hline \multicolumn{20}{|c|}{ Results - Advanced Lecture Group } \\
\hline \multirow{2}{*}{\multicolumn{2}{|c|}{ Question \# }} & \multicolumn{18}{|c|}{ Subjects } \\
\hline & & 11 & & & 4 & & & & 8 & 110 & & 112 & & 4415 & $116 / 17$ & 718 & & 202 & 21 \\
\hline \multirow{12}{*}{$\begin{array}{l}\text { Section One } \\
1-12\end{array}$} & 1 & & & & 0 & & 01 & & & & & & & & 10 & & & & \\
\hline & 2 & & & & & & & & & & & & & & I & $T$ & 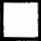 & 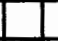 & 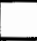 \\
\hline & 3 & & & & & & & & & & & & & & & & & & \\
\hline & 4 & & & & & & & & & & & & & & & & & & \\
\hline & 5 & & & & & & & & & & & & & & 0 & & & & 0 \\
\hline & 6 & & & & & & & & & & & & & & & & & & \\
\hline & 7 & 0 & & $\overline{0}$ & $\overline{0}$ & 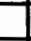 & & 0 & & 0 & 0 & 0 & & & \begin{tabular}{|l|l|l|l|}
0 & 0 \\
\end{tabular} & 0 & & & 0 \\
\hline & 8 & & & & & 0 & & 0 & & & & 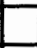 & & & & 0 & & & 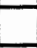 \\
\hline & 9 & & & & & & & & & & 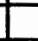 & 0 & & & $L$ & 1 & & & L \\
\hline & 10 & 0 & & & & & & & & & 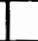 & 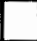 & & & 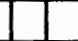 & 0 & & & 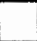 \\
\hline & 11 & & & & & & & & & & & & & & 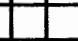 & & & & \\
\hline & 12 & & & & & & & & & & & & & & & & & & \\
\hline \multirow{18}{*}{$\begin{array}{c}\text { Section Two } \\
13-29\end{array}$} & 13 & & & & & & & & & & & & & & & & & & \\
\hline & 14 & 0 & & & 0 & & & & & & 0 & 0 & & & 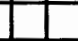 & 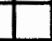 & 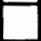 & & 0 \\
\hline & 15 & & & & 0 & & 0 & & & & & - & & 0 & 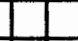 & 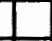 & 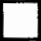 & & 0 \\
\hline & 16 & & & & & & & & & & . & E & & & 0 & & & & \\
\hline & 17 & 10 & & & & & & & & & 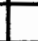 & - & & & 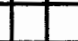 & & & 0 & \\
\hline & 18 & 0 & 0 & & & 0 & - & & & & & 0 & & & 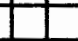 & & & 0 & 0 \\
\hline & 19 & & 0 & & & 0 & & & & & 0 & 0 & & & 0 & & & \begin{tabular}{l|l}
0 & 1 \\
\end{tabular} & 0 \\
\hline & 20 & & & $\overline{0}$ & & & $\overline{0}$ & & & & & 0 & & & & to & & & \\
\hline & 21 & 0 & & & & 0 & $\overline{0}$ & 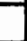 & & & 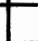 & - & & & 0 & & & 0 & 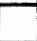 \\
\hline & 22 & 0 & & & 0 & & & 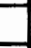 & & & 0 & 0 & & 0 & & 0 & & & 0 \\
\hline & 23 & 0 & 0 & & $\overline{0}$ & & 0 & $\overline{0}$ & & 0 & & & 0 & & \begin{tabular}{|l|l}
0 & 0
\end{tabular} & 10 & 0 & & \\
\hline & 24 & 0 & & & & 0 & & 0 & & 0 & 0 & 0 & & & 0 & 0 & $L$ & & 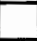 \\
\hline & 25 & & 0 & & & & & & & & & 0 & & & & & $\overline{0}$ & & 0 \\
\hline & 26 & & & 0 & & & & & 0 & 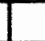 & 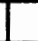 & 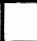 & & & 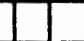 & 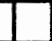 & & & 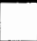 \\
\hline & 27 & & & 0 & $\overline{0}$ & & 0 & 0 & & 0 & 0 & 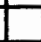 & & 0 & 0 & 0 & & & E \\
\hline & 28 & & & & & & 0 & & & & & 0 & & & & & & & 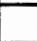 \\
\hline & 29 & & & & & & & & & & & & & & & & & & \\
\hline & 30 & & & $\overline{0}$ & & & & & & & & & & & & & & & 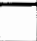 \\
\hline \multirow{8}{*}{$\begin{array}{l}\text { Section Three } \\
30-38\end{array}$} & 31 & & & & & $\overline{0}$ & & & & & & & & & & & & & 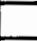 \\
\hline & 32 & & & & & & & & & & 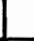 & L & & & 0 & & 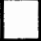 & & 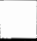 \\
\hline & 33 & & & & & & & & & & & & & & & & & & \\
\hline & 34 & & & & & 0 & & & & & & & & & & & & & \\
\hline & 35 & & & & 0 & & & & & & 0 & 0 & & & & 0 & & & 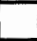 \\
\hline & 36 & & & & $\overline{0}$ & & & & & 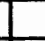 & & & & 0 & & & & & 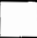 \\
\hline & 37 & & & & & & 0 & & & 0 & & & & & & & [ & & 0 \\
\hline & 38 & & & $\overline{0}$ & & & & & & & & & & & 0 & 0 & & & \\
\hline \multirow{7}{*}{$\begin{array}{l}\text { Section Four } \\
39-45\end{array}$} & 39 & & & & & & & & & & & & & & & & & & \\
\hline & 40 & & & & & & & & & & & & & & & & & & \\
\hline & 41 & & & & & & & & & & & & & & & & & & \\
\hline & 42 & & & & & & & & & & & & & & & & & & \\
\hline & 43 & 10 & & & & & & & & 0 & & & & 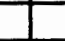 & & & 0 & & 0 \\
\hline & 44 & & & & & & & & 0 & & & & & & & & & & \\
\hline & 45 & 0 & & & & & & & 0 & & & & & 0 & & & & & \\
\hline \multicolumn{2}{|c|}{ Totals $=$} & & & & & & & & & & & & & & & 43 & & 413 & 35 \\
\hline "0" $=$ inc & & & & & & & & & & & ean & s s & & $=38.9$ & & & & & \\
\hline
\end{tabular}

Figure 9. Response patterns of the advanced lecture group on the original 45 - item questionnaire. 


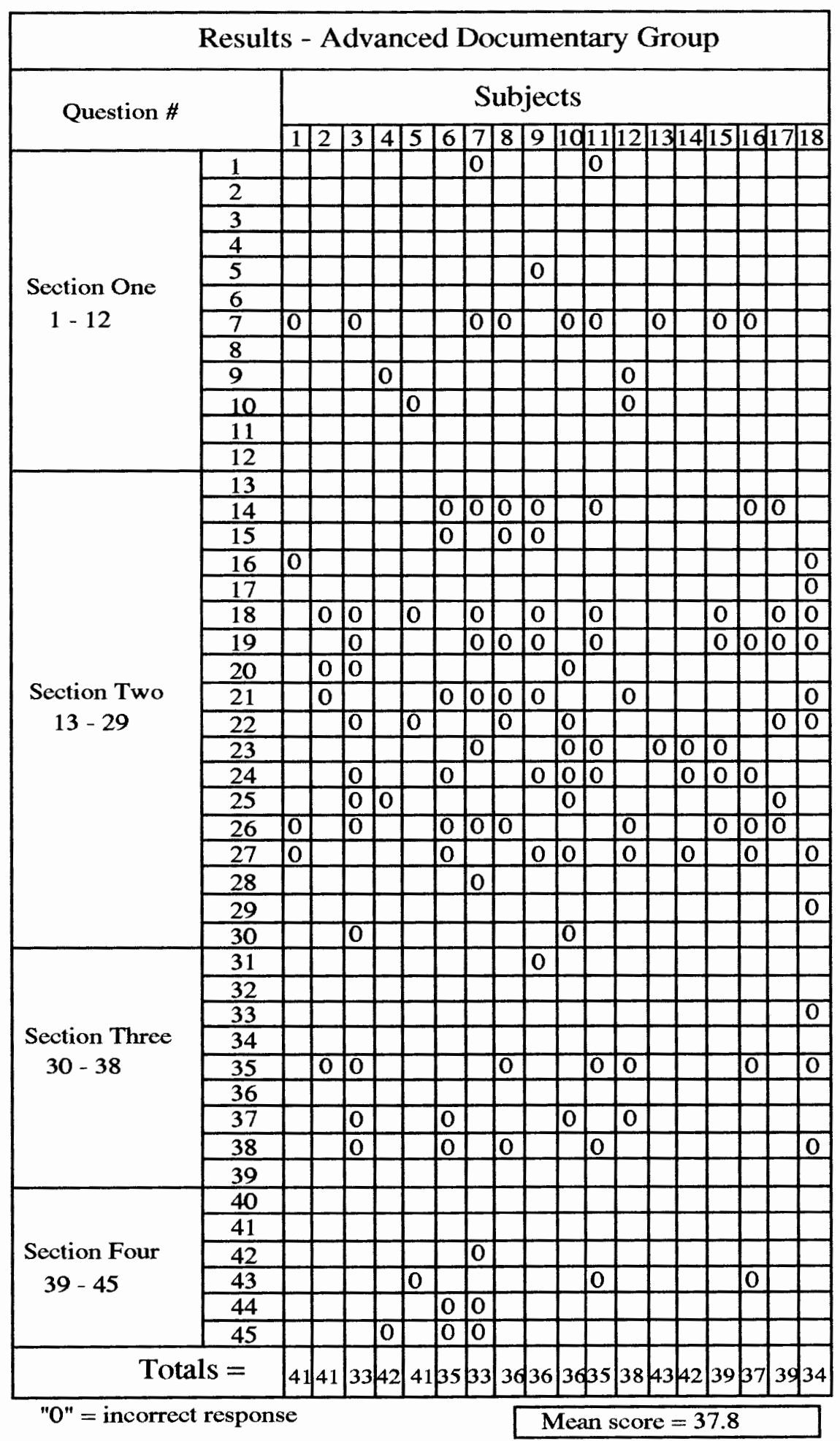

Figure 10. Response pattern of the advanced documentary group on the original 45 -item questionnaire. 


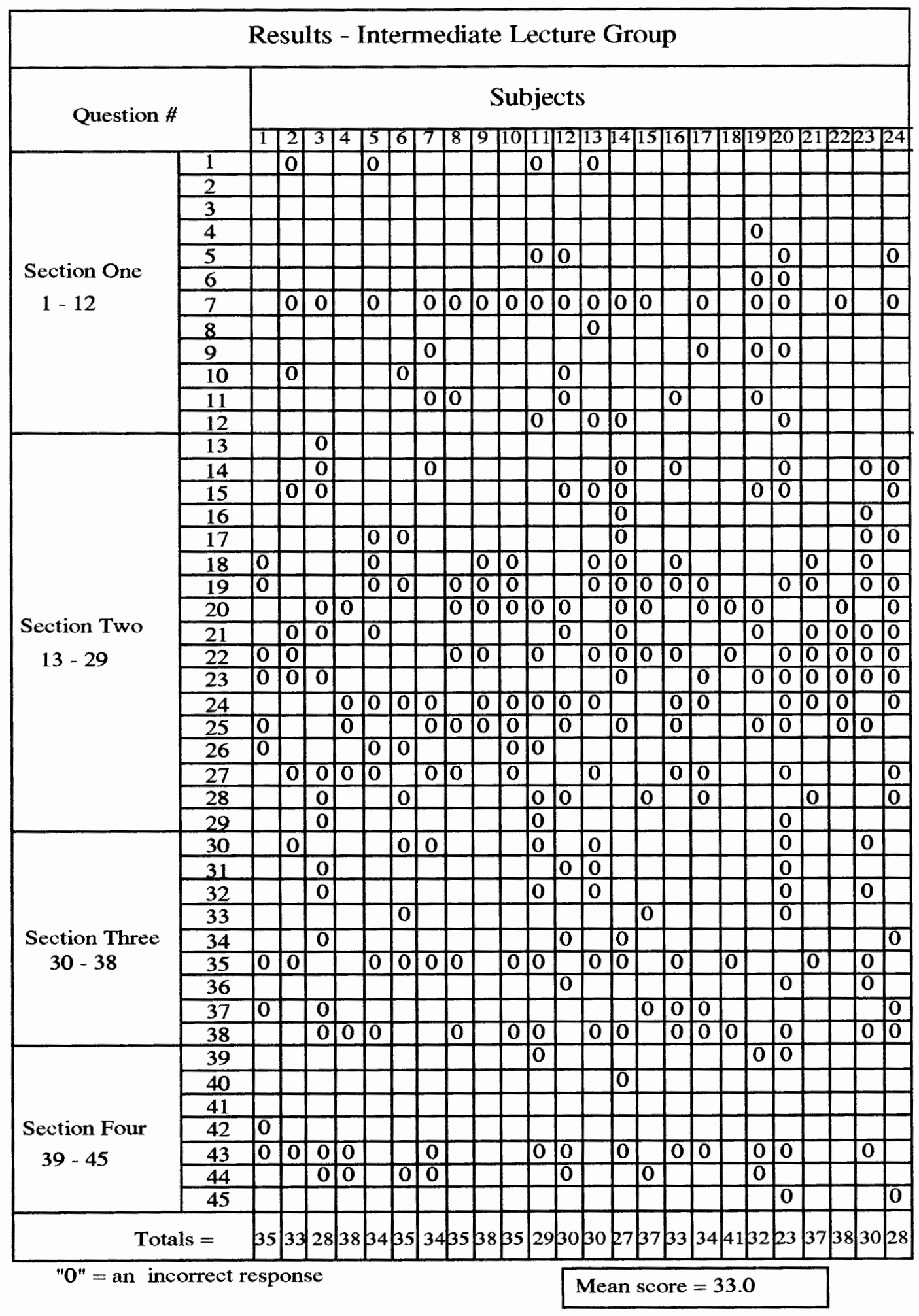

Figure 11. Response patterns of the intermediate lecture group on the original 45 - item questionnaire. 


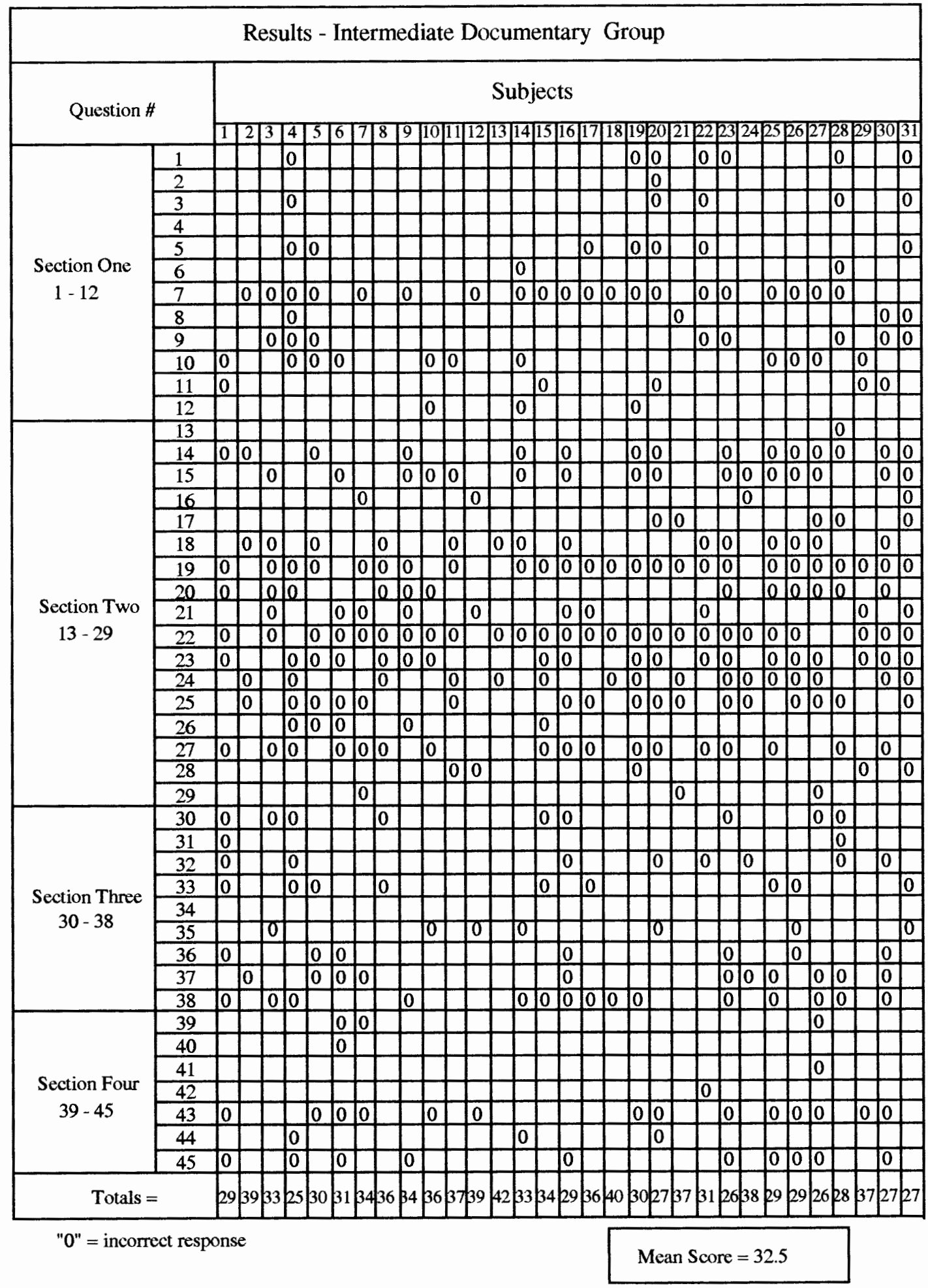

Figure 12. Response patterns of the intermediate documentary group on the original 45 - item questionnaire. 


\section{APPENDIX B}

SCRIPT AND VISUAL DESCRIPTION

OF THE DOCUMENTARY VIDEO 


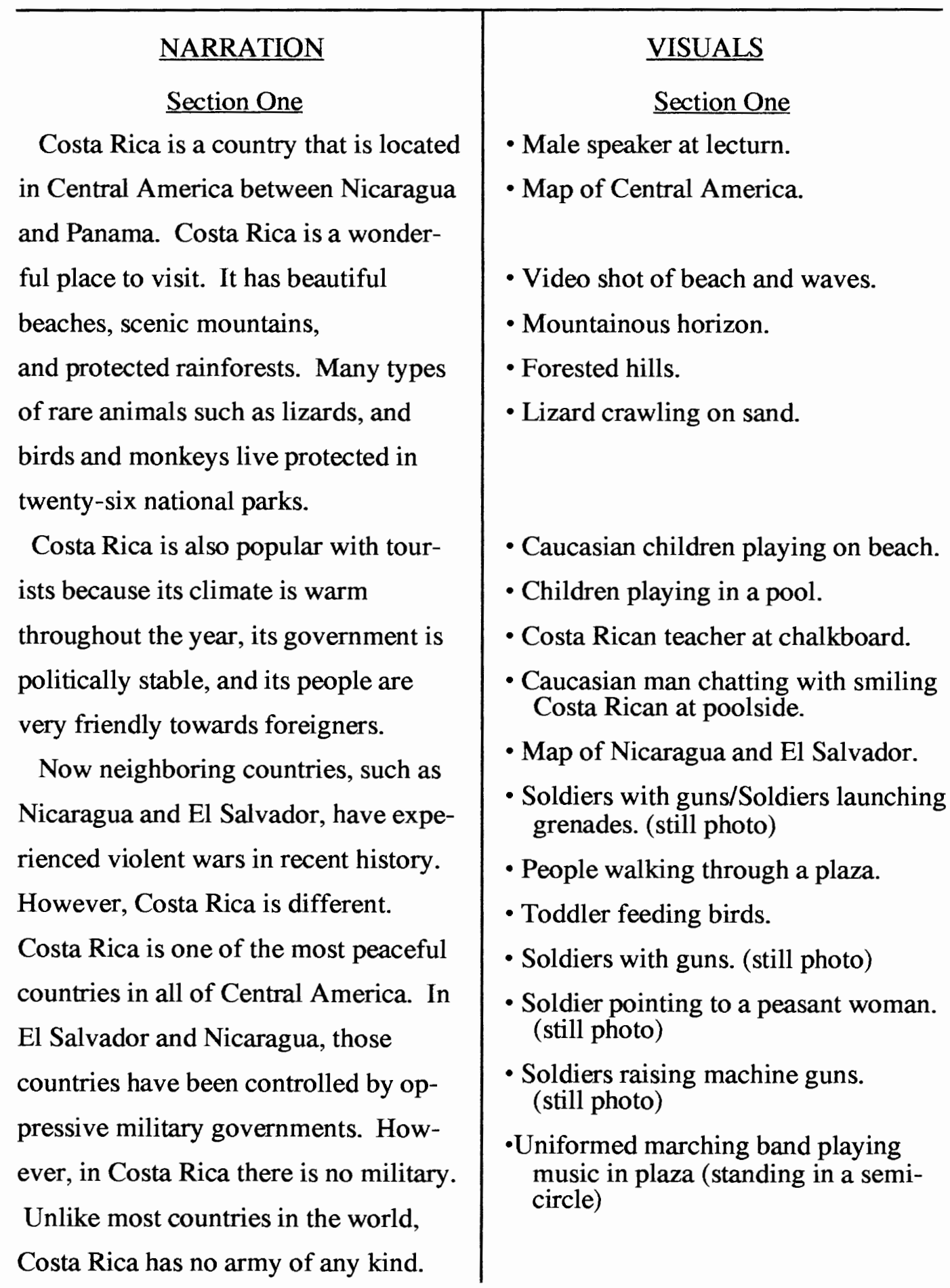


This is because in 1948 there was a brief civil war is Costa Rica and the leaders who won that civil war made changes in the government to ensure that Costa Rica would always be a Democratic nation. And one of the primary things they did was they abolished the army. Ever since then, Costa Ricans have enjoyed free and peaceful Democratic elections every four years. and Costa Ricans are so proud of their democracy that each time a new president is elected, in all the cities across Costa Rica, Costa Ricans flood the streets and celebrate.

I was a student in Costa Rica in 1990. I studied Spanish in the capital city called San Jose. Now San Jose is located in the central mountains of Costa Rica. It is the center of all government and international business for Costa Rica. Now compared to other major cities in Central America, San Jose is very small. It is not known for for having famous monuments or historical buildings. But it is generally a very safe city to visit and this is why it is so popular with tourists.
- Soldiers walking in ranks.

(Still photo)

- Exterior of a brown government building.

- Costa Rican flag outside brown government building.

- Slow pan of a long banner, with the colors of the Costa Rican flag, draped over the side of a building.

- Two women at a political rally. (still photo)

- Boy in "Calderon" T-shirt. (still photo)

- Flowers outside government building.

- People in a rally with flags. (still photo)

- Researcher posing with a Costa Rican family. (still photo)

- Wide shot of downtown San Jose from a tall building.

- Exterior of a building.

- People boarding a city bus.

- Man reading a news paper in front of a structure with stone arches.

- Flowers in front of a building.

- People walking on the street.

- Caucasian man and woman eating ice cream cones. 
Section Two
Religion is a very important part of the culture in costa Rica. Now in general, the main religion is Christianity. But there are two distinct types of Christians in Costa Rica. You have the Catholics and a group called Evangelical Christians. Now the Catholic church is still the largest and most dominant church in all of Central America and most Costa Ricans consider themselves Catholic. However, there is a small portion of the population that considers itself evangelical and there are many different beliefs between the two groups: different theological beliefs, political beliefs, and, importantly, different worship styles. Catholics generally worship in large cathedrals and their worship services are very much like ceremonies, very formal, with priests.

However, Evangelical churches are much like small communities. They meet in smaller buildings, in fewer numbers, and their services are much less formal. I had an opportunity to visit a number of evangelical churches while I stayed in Costa Rica. And one
- People clapping and singing inside of a small church.

- A crowd of people walking down a street, some carrying a wooden statue of Christ. (Easter procession)

- Choir singing inside a church.

- Another shot of the Easter proces sion.

- Man praying, holding a microphone.

- Second man praying, standing at a microphone.

- Girls singing.

- Exterior shot of a large, white cathedral.

- Second shot of the cathedral.

- Still photo of Pope John Paul.

- Man standing at a podium.

- Women in pews.

- Children singing.

- Congegration of people waving arms in the air. 
church was located in a village called Los Guidos. Now Los Guidos is a very poor village located just outside San Jose. The people there live in wooden shacks, small concrete homes, and children have to play in dirt roads. and Los Guidos did not have electricity or running water until 1988, only 5 years ago. Now in April of 1990, Evangelical Christians from all around Costa Rica came to Los Guidos to celebrate the finished construction of the first Evangelical church in Los Guidos. Now this church was quite special because all of the people who worked on the church were volunteers. None of the workers who built the church were paid. In fact, many of the supplies for the church were donated by churches in Costa Rica and in the United States. so it was certainly a community project. So it makes sense that a community of Christians came to celebrate its completed construction. and believe me, the people were very excited. Inside, the church was filled with people. There were musicians playing organs and guitars and tambourines, and people clapped their hands and raised
- People walking into a small white building.

- Children riding bikes on a dirt street.

- Small boy standing on a dirt road.

-People walking in a small group, man carries a suitcase.

- Inside the church building, women talk in pews.

- More people walking toward the the church.

- Girls talking, one has a tambourine.

- People singing inside.

- Man playing an electric keyboard. 
their arms, and sang loudly, with much enthusiasm. Eventually though, the music quieted and a man came before the group and spoke. And his name was Jorge Martinez. Jorge was the new pastor of the Los Guidos church. Jorge also was a pastor in San Jose, and during the construction he would travel from San Jose to Los Guidos every week to make sure the construction was going on properly. So he was a very busy man and he was definitely the one person who was most pleased to finally see the church constructed.

\section{Section Three}

As well as visiting Los Guidos, I also travelled to villages that were located far away from San Jose, way up in the mountains. One such village was called Sabanias. Sabanias is a wonderful, quiet village. It is located beneath steep hills of green trees and vegetation. The people who live in Sabanias generally work on coffee farms and on large plantations that grow sugar cane. They also raise chickens and cows and will use horses to travel to other villages in the mountains. The church I vis
- People waving arms and singing.

- Man speaking, holding a microphone, standing behind a lecturn.

- Researcher standing at a lecturn reciting the narration.

- Dusty village street.

- Zoom of surrounding hills.

- Tractor driving down the street.

- Chicken walking on side of a street.

- Boy leading a horse down the street. 


\begin{abstract}
ited in Sabanias was a small concrete building painted bright blue. And inside the floor was swept clean but there were only 8 benches upon which for [sic] people to sit. Now on this day I was travelling with Jorge Martinez, who I just mentioned, and an American named Fred Roberts. Now Fred Roberts was a teacher from the United States and he was also studying Spanish in San Jose as I was. And he wanted to travel throughout the country and teach at as many churches as he could.
\end{abstract} Now on this day there were about 20 other people in the church. There were more children than adults I can assure you. And the pastor of the church, his name was Francisco Gusman. Now Francisco was an interesting man because he had no education as a pastor. During the week he worked on a coffee farm and then on Sundays he would bring his old guitar to church and he and his wife would lead songs and he would teach. Now the people in this church don't normally receive visitors. So they were particularly excited to greet us because we were from the United States.
- Exterior of a small blue church.

- Close up of a mural on the church.

-Woman leading songs and clapping.

- Men eating, standing at the side of a minivan. One man sits in the passenger seat with the door open.

- Caucasian man standing and speaking at a lecturn.

- Small group of children in the church singing.

-Woman singing, man playing a guitar.

- Zoom in on the man playing the guitar. 


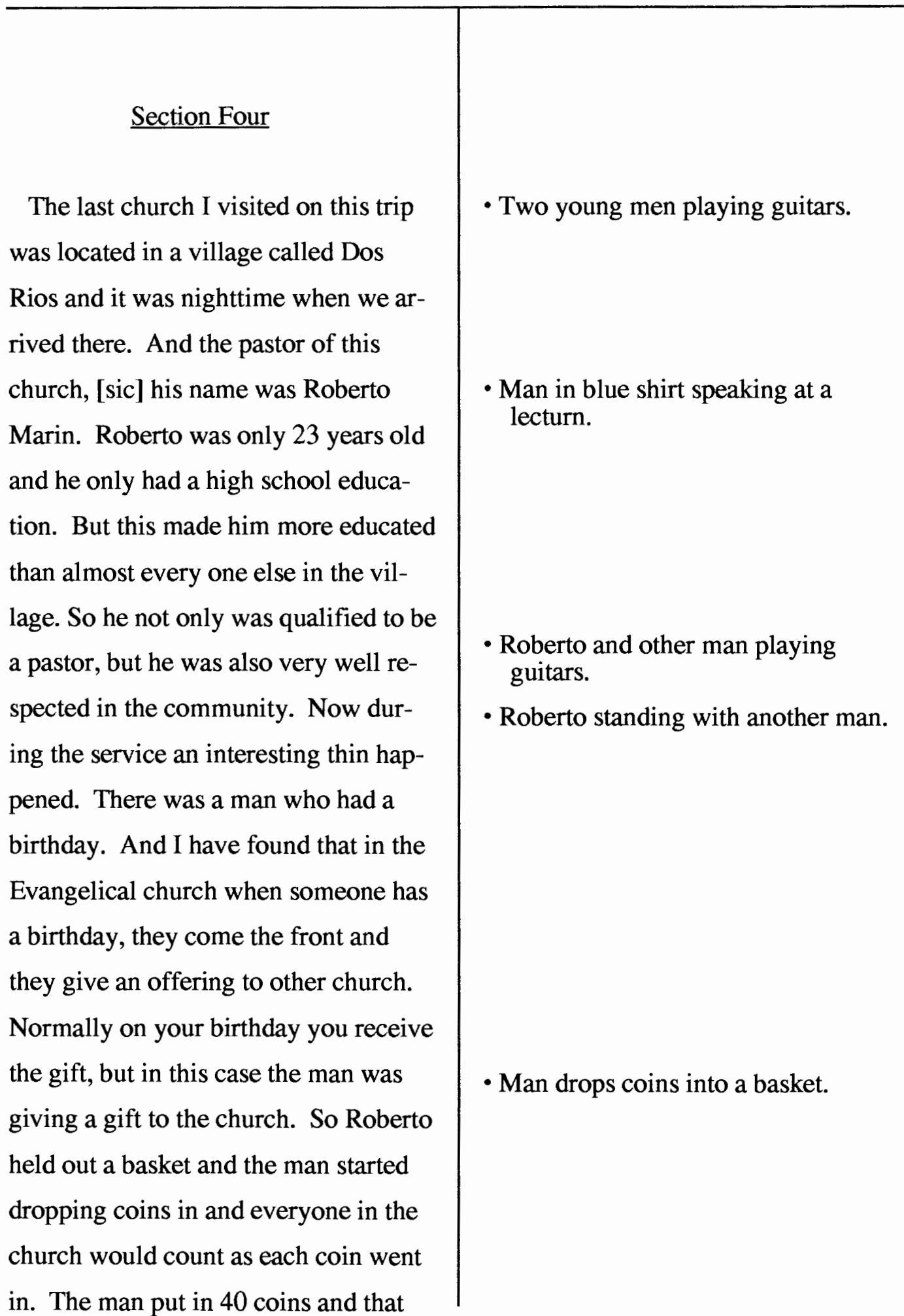


was how old he was. Then Roberto asked him if he had anything to say to the church. The man first thanked God for his family and thanked them for their support. He also told them how happy he was to have a job on a sugar plantation. And once he finished sharing the entire church broke into song and sang him a very special Costa Rican version of the birthday song.
- Close-up of birthday man speaking.

- Shot of people in pews clapping and singing. 
APPENDIX C

TABLES 


\section{TABLE VIII}

\section{DIFFICULTY VALUES OF EACH QUESTION ON THE ORGINIAL 45 - ITEM QUESTIONNAIRE WITH ALL SCORES COMBINED}

\begin{tabular}{|c|c|c|}
\hline & Difficulty Values & Std. Dev \\
\hline Q1 & .8191 & .3870 \\
\hline Q2 & .9894 & .1031 \\
\hline Q3 & .9468 & .2256 \\
\hline Q4 & .9894 & .1031 \\
\hline Q5 & .8511 & .3579 \\
\hline Q6 & .9574 & .2029 \\
\hline Q7 & .4043 & .4934 \\
\hline Q8 & .9043 & .2958 \\
\hline Q9 & .8404 & .3682 \\
\hline Q10 & .7979 & .4037 \\
\hline Q11 & .8936 & .3100 \\
\hline Q12 & .9255 & .2639 \\
\hline Q13 & .9787 & .1451 \\
\hline Q14 & .6383 & .4831 \\
\hline Q15 & .6702 & .4727 \\
\hline Q16 & .9043 & .2958 \\
\hline Q17 & .8617 & .3471 \\
\hline Q18 & .5957 & .4934 \\
\hline Q19 & .4043 & .4934 \\
\hline Q20 & .6489 & .4799 \\
\hline Q21 & .6596 & .4764 \\
\hline Q22 & .4255 & .4971 \\
\hline Q23 & .5000 & .5027 \\
\hline Q24 & .5000 & .5027 \\
\hline $\mathrm{Q} 25$ & .5957 & .4934 \\
\hline Q26 & .7872 & .4115 \\
\hline Q27 & .5000 & .5027 \\
\hline Q28 & .8298 & .3778 \\
\hline Q29 & .9255 & .2639 \\
\hline Q30 & .7979 & .4037 \\
\hline Q31 & .9149 & .2805 \\
\hline Q32 & .8511 & .3579 \\
\hline Q33 & .8617 & .3471 \\
\hline Q34 & .9468 & .2256 \\
\hline Q35 & .6596 & .4764 \\
\hline Q36 & .8723 & .3355 \\
\hline Q37 & .7447 & .4384 \\
\hline Q38 & .6064 & .4912 \\
\hline Q39 & .9362 & .2458 \\
\hline Q40 & .9787 & .1451 \\
\hline Q41 & .9894 & .1031 \\
\hline Q42 & .9681 & .1767 \\
\hline Q43 & .6383 & .4831 \\
\hline Q45 & .8085 & .3956 \\
\hline
\end{tabular}


TABLE IX

\section{RELIABILITY ANALYSIS OF THE ORIGINAL 45 - ITEM QUESTIONNAIRE WITH ALL SCORES COMBINED}

\begin{tabular}{|c|c|c|c|c|c|}
\hline & $\begin{array}{c}\text { Scale Mean } \\
\text { if Item Deleted }\end{array}$ & $\begin{array}{l}\text { Scale Variance } \\
\text { if Item Deleted }\end{array}$ & $\begin{array}{l}\text { Corrected } \\
\text { Itern-Total } \\
\text { Correlation }\end{array}$ & $\begin{array}{r}\text { Item-Total } \\
\text { Covariance }\end{array}$ & $\begin{array}{l}\text { Reliability } \\
\text { (Alpha if } \\
\text { Item Deleted }\end{array}$ \\
\hline Q1 & 34.3617 & 23.7817 & .2972 & .7105 & .7546 \\
\hline Q2 & 34.1915 & 24.8877 & .1503 & .0880 & .7608 \\
\hline Q3 & 34.2340 & 24.3102 & .3110 & .3968 & .7563 \\
\hline Q4 & 34.1915 & 24.9952 & .0457 & .0342 & .7619 \\
\hline Q5 & 34.3298 & 23.6428 & .3683 & .7692 & .7521 \\
\hline $\mathrm{Q} 6$ & 34.2234 & 24.5410 & .2342 & .2766 & .7584 \\
\hline Q7 & 34.7766 & 23.4227 & .2904 & .9369 & .7545 \\
\hline Q8 & 34.2766 & 24.6323 & .1134 & .2541 & .7613 \\
\hline Q9 & 34.3404 & 23.8183 & .3058 & .6857 & .7544 \\
\hline Q10 & 34.3830 & 24.2604 & .1583 & .4778 & .7604 \\
\hline Q11 & 34.2872 & 24.4435 & .1675 & .3528 & .7596 \\
\hline Q12 & 34.2553 & 24.2782 & .2711 & .4222 & .7567 \\
\hline Q13 & 34.2021 & 24.7652 & .1847 & .1544 & .7599 \\
\hline Q14 & 34.5426 & 22.6810 & .4648 & 1.3027 & .7453 \\
\hline Q15 & 34.5106 & 22.8977 & .4271 & 1.1893 & .7475 \\
\hline Q16 & 34.2766 & 24.8689 & .0327 & .1358 & .7638 \\
\hline Q17 & 34.3191 & 24.1336 & .2343 & .5799 & .7572 \\
\hline Q18 & 34.5851 & 24.4819 & .0671 & .4072 & .7662 \\
\hline Q19 & 34.7766 & 22.8850 & .4077 & 1.2057 & .7482 \\
\hline Q20 & 34.5319 & 23.6280 & .2561 & .8276 & .7563 \\
\hline Q21 & 34.5213 & 24.3813 & .0945 & .4493 & .7644 \\
\hline Q22 & 34.7553 & 23.6922 & .2302 & .8039 & .7578 \\
\hline $\mathrm{Q} 23$ & 34.6809 & 23.5315 & .2602 & .8871 & .7562 \\
\hline Q24 & 34.6809 & 24.1551 & .1306 & .5753 & .7631 \\
\hline Q25 & 34.5851 & 23.5357 & .2661 & .8803 & .7558 \\
\hline Q26 & 34.3936 & 25.0800 & -.0476 & .0712 & .7693 \\
\hline Q27 & 34.6809 & 23.8970 & .1838 & .0743 & .7603 \\
\hline Q28 & 34.3511 & 24.5313 & .1012 & .3322 & .7625 \\
\hline Q29 & 34.2553 & 24.3642 & .2376 & .3792 & .7576 \\
\hline Q30 & 34.3830 & 23.4862 & .3587 & .8649 & .7518 \\
\hline Q31 & 34.2660 & 24.1973 & .2815 & .4672 & .7562 \\
\hline Q32 & 34.3298 & 23.3632 & .4513 & .9089 & .7488 \\
\hline Q33 & 34.3191 & 24.0046 & .2729 & .5844 & .7558 \\
\hline Q34 & 34.2340 & 24.5038 & .2231 & .3000 & .7584 \\
\hline Q35 & 34.5213 & 24,5318 & .0623 & .3741 & .7660 \\
\hline Q36 & 34.3085 & 23.8500 & .3327 & .6577 & .7537 \\
\hline Q37 & 34.4362 & 23.9690 & .2078 & .6381 & .7585 \\
\hline Q38 & 34.5745 & 22.7847 & .4323 & 1.2547 & .7469 \\
\hline Q39 & 34.2447 & 24.3158 & .2792 & .3988 & .7567 \\
\hline Q40 & 34.2021 & 24.8082 & .1548 & .1329 & .7604 \\
\hline Q41 & 34.1915 & 24.8662 & .1713 & .0987 & .7606 \\
\hline Q42 & 34.2128 & 24.9650 & .0321 & .0596 & .7624 \\
\hline Q43 & 34.5426 & 23.1971 & .3487 & 1.0466 & .7515 \\
\hline Q44 & 34.3191 & 24.5852 & .1009 & .2741 & .7621 \\
\hline Q45 & 34.3723 & 23.7201 & .3053 & .7447 & .7521 \\
\hline
\end{tabular}

Reliability Alpha $=.7617$ 
TABLE X

RELIABILITY ALPHAS FOR FINAL

30-ITEM QUESTIONNAIRE WITH ALL SCORES COMBINED

\begin{tabular}{|c|c|}
\hline Question & $\begin{array}{l}\text { Reliab } \\
\text { (Alpha } \\
\text { Item De }\end{array}$ \\
\hline Q1 & .7546 \\
\hline Q3 & .7820 \\
\hline Q5 & .7778 \\
\hline Q7 & .7827 \\
\hline Q8 & .7869 \\
\hline Q9 & .7802 \\
\hline Q10 & .7874 \\
\hline Q11 & .7851 \\
\hline Q12 & .7827 \\
\hline Q14 & .7725 \\
\hline Q15 & .7738 \\
\hline Q17 & .7863 \\
\hline Q19 & .7783 \\
\hline Q20 & .7828 \\
\hline Q22 & .7833 \\
\hline Q23 & .7810 \\
\hline Q25 & .7826 \\
\hline Q27 & .7845 \\
\hline Q29 & .7836 \\
\hline Q30 & .7767 \\
\hline $\mathrm{Q} 31$ & .7815 \\
\hline Q32 & .7733 \\
\hline Q33 & .7812 \\
\hline Q34 & .7854 \\
\hline Q36 & .7770 \\
\hline Q37 & .7844 \\
\hline Q38 & .7735 \\
\hline Q39 & .7825 \\
\hline Q43 & .7775 \\
\hline Q45 & .7782 \\
\hline
\end{tabular}

Standardized Item Alpha $=.7902$ 


\section{APPENDIX D}

\section{SAMPLE ANSWERS FROM}

ORIGINAL QUESTIONNAIRE 
Answer each question based upon what you hear in the narration.

Tho tape will be stopped four times so you can answer the questions.

Sample:

1. Is Costa Rica part of Central America? (Yes/No)

Section 1 - Costa Rica

1. Is Costa Rica famous for having rainforests? (Yes No)

2. Does Costa Rica bove any mational perbs? (Yea No)

3. Is Costa Rica popular with tourists? (Y5/ No)

4. Are Costa Ricens friendly to touriets? (Ya) No)

5. Is Costa Rica a violent country? (Yes Na)

6. Does Costa Rica have a large army? (Yes (No)

7. In 1948, did Costa Ricans fight a war againat E Salvador? (Yea/ No)

8. Do Costa Ricans have elections every six years? (Yes No)

9. Was Scott Thompeon an English teacher in Costn Rica? (Yes (No)

10. Is Coetn Rica's government located in Sen Jowe? (Yes (No)

11. Compared to other capital cities, is Sen Jome large? (Pes No)

12. Is San Jose a dangerous city to viait? (Yes No)

Section 2 - The villnge called "Los Gubdos".

13. Is religion an importunt purt of Coest Ricen culture? (Yes/ No)

14. Are Evangelical Chriatians the lergett retigious group in Com Bica? (Yen/No)

15. Do moat Costa Ricans coasider themelves Evangelical Chrivtims? (Yes/No) -

16. Are Evangelical Christians and Contholics very different? (Yeg/No)

17. Do Cathotics worahip in a formal way? (Ye/No)

18. Are Catholic churctes large? (Ya) No)

19. Are Cutholic churches libe small communities? (Yes (No)

20. Is Los Guidos located far away from Son Jome? (Yea (No) 
21. Did the people in Los Guidos live in concrete homes? (Yes (No)

22. Did Los Guidos have electricity or clean water in 1990 ? (Yes (Ng)

23. Did the Christians come to Los Guidos to celebrate a Christian holiday? (Yes No) -

24. Was the new church a Catholic church? (Yes No)

25. Were the warkers who built the church paid much money ? (Yes (No))

26. Did people in the United States donate supplies for the church? (Yes / No)

27. Was Jarge Martenes the mayor of Los Guidos? (Yes) No)

28. Did Jorge Mertenez also work in San Jowe? (Yeg/No)

29. Did Jorge Martenes help with the construction of the church? (Yea/ No)

Section 3-The villoge called "Sabanias".

30. Is Sabenias located near San Jose? (Yes) No)

31. Do villagers in Sabenias work on coffee furms? (Year No)

32. Did the church have more than ten benches to at on? (Yes (No)

33. Was Fred Roberts a busineseman from the United Strtes? (Yes (No)

34. Did Fred Roberts study Spanish in San Jose? (Yea/ No)

35. Did Fred Roberts want to visit many churches in Coeta Rica? (Yes / Noo)

36. Did Franscisco Guamen have sa colucation to be a pastor? (Yes No)

37. Did Franciso Guamen wark on a werer plantation during the week? (Yes (No)

38. Did the people in the church receive visitars oftea? (Yes (No)

Section 4 - The villige called "Dos Rios".

39. Was Roberto Marin 33 yeers old? (Yes (f)

40. Did Roberto Marin have a high school oducation? (Ye/No)

41. Was Roberto Marin respectod in the coumunity? (Ya) No)

42. Did the man give coins as a gift to the church? (Yo) No)

43. Was the man celebrating the birth of his chilas (Yes/ No)

44. Did the man have a family? (Ye/ / No)

45. Did the men wark on a coffec plentation? (Yes /No) 